\title{
Attribution of Dry and Wet Climatic Changes over Central Asia
}

\author{
Yu Ren, ${ }^{\mathrm{a}}$ Haipeng Yu, ${ }^{\mathrm{b}}$ CHenXi Liu,,${ }^{\mathrm{a}}$ Yongli He, ${ }^{\mathrm{a}}$ JianPing Huang, ${ }^{\mathrm{c}, \mathrm{a}}$ Lixia Zhang, ${ }^{\mathrm{d}}$ HuAncui Hu, \\ Qiang Zhang, ${ }^{\mathrm{f}}$ SiYu Chen, ${ }^{\mathrm{a}}$ XiaOyue LiU, ${ }^{\mathrm{a}}$ Meng Zhang, ${ }^{\mathrm{g}}$ Yun Wei, ${ }^{\mathrm{a}}$ YaOXian Yan, ${ }^{\mathrm{b}}$ Weiwei Fan, ${ }^{\mathrm{b}}$ And \\ JIE ZHOU ${ }^{\mathrm{a}}$ \\ ${ }^{\text {a }}$ College of Atmospheric Sciences, Lanzhou University, Lanzhou, China \\ ${ }^{\mathrm{b}}$ Key Laboratory of Land Surface Process and Climate Change in Cold and Arid Regions, \\ Northwest Institute of Eco-Environment and Resources, Chinese Academy of Sciences, Lanzhou, China \\ ${ }^{\mathrm{c}}$ Collaborative Innovation Center for Western Ecological Safety, Lanzhou, China \\ d LASG, Institute of Atmospheric Physics, Chinese Academy of Sciences, Beijing, China \\ e Atmospheric Sciences and Global Change Division, Pacific Northwest National Laboratory, Richland, Washington \\ ${ }^{\mathrm{f}}$ Key Open Laboratory of Arid Climate Change and Disaster Reduction of CMA, \\ Key Laboratory of Arid Climate Change and Reducing Disaster of Gansu Province, Institute of Arid Meteorology, \\ China Meteorological Administration, Lanzhou, China \\ ${ }^{\mathrm{g}}$ Department of Atmospheric and Oceanic Sciences and Institute of Atmospheric Sciences, Fudan University, Shanghai, China
}

(Manuscript received 28 April 2021, in final form 13 November 2021)

\begin{abstract}
Central Asia $\left(\mathrm{CA} ; 35^{\circ}-55^{\circ} \mathrm{N}, 55^{\circ}-90^{\circ} \mathrm{E}\right)$ has been experiencing a significant warming trend during the past five decades, which has been accompanied by intensified local hydrological changes. Accurate identification of variations in hydroclimatic conditions and understanding the driving mechanisms are of great importance for water resource management. Here, we attempted to quantify dry/wet variations by using precipitation minus evapotranspiration $(P-E)$ and attributed the variations based on the atmosphere and surface water balances. Our results indicated that the dry season became drier while the wet season became wetter in CA for 1982-2019. The land surface water budget revealed precipitation $(96.84 \%)$ and vapor pressure deficit $(2.26 \%)$ as the primary contributing factors for the wet season. For the dry season, precipitation $(95.43 \%)$, net radiation $(3.51 \%)$, and vapor pressure deficit $(-2.64 \%)$ were dominant factors. From the perspective of the atmospheric water budget, net inflow moisture flux was enhanced by a rate of $72.85 \mathrm{~kg} \mathrm{~m}^{-1} \mathrm{~s}^{-1}$ in the wet season, which was mainly transported from midwestern Eurasia. The increase in precipitation induced by the external cycle was $11.93 \mathrm{~mm}$ (6 months $)^{-1}$. In contrast, the drying trend during the dry season was measured by a decrease in the net inflow moisture flux $\left(74.41 \mathrm{~kg} \mathrm{~m}^{-1} \mathrm{~s}^{-1}\right)$ and reduced external moisture from midwestern Eurasia. An increase in precipitation during the dry season can be attributed to an enhancement in local evapotranspiration, accompanied by a $4.69 \%$ increase in the recycling ratio. The compounding enhancements between wet and dry seasons ultimately contribute to an increasing frequency of both droughts and floods.
\end{abstract}

KEYWORDS: Atmosphere-land interaction; Hydrologic cycle; Water budget/balance

\section{Introduction}

Central Asia (CA) is one of the largest arid and semiarid regions [almost the entire area has an aridity index $(\mathrm{AI})<$ 0.65 ] in the midlatitudes, characterized by very low volumes of annual precipitation and soil moisture, except for a few mountainous areas. Evapotranspiration is strongly restricted by the supply of water (Fig. 1) (Chen et al. 2011; Hu et al. 2014). As CA is mainly covered by deserts, grasslands, or shrubs, it is more vulnerable than humid regions to climatic changes (Li et al. 2015; Huang et al. 2016; Yin et al. 2016). The annual mean temperature in CA has increased significantly in the past hundred years, with an accelerating warming rate (approximately $0.33^{\circ} \mathrm{C} \mathrm{decade}^{-1}$ ) from 1979 to 2011 , which is much stronger than that of global land areas (Chen et al. 2009; IPCC 2013; Hu et al. 2014; Peng et al. 2019). Previous investigations have examined the response of hydrological conditions to warming trends, including an increase in evapotranspiration and runoff ( $\mathrm{Li}$ et al. 2017), glacial degradation (He et al. 2015), reduced terrestrial water storage (Chen et al.

Corresponding author: Haipeng Yu, yuhp@lzb.ac.cn
2016; Deng and Chen 2017), and rivers appearing to have glacial inflection points (Chen et al. 2015). However, there has not been a comprehensive investigation into how the dry and wet climatic conditions have changed. Identifying this issue is essential for improving our understanding of the regional water cycle, formulating water resource management policies, and improving prediction skills under climate changes. These factors are all closely associated with implications for socioeconomic development and ecosystem stability.

Previous studies exploring wetting and drying trends have predominantly focused on precipitation trends (e.g., Shi et al. 2007; Chou et al. 2013; Li et al. 2016; Peng and Zhou 2017; Wang et al. 2020). Precipitation is a crucial aspect of the water supply in arid and semiarid regions. Summer precipitation in CA significantly increased by $20.78 \%$ from 1961 to 2013 (Peng et al. 2018), with an abrupt increase in 1998 (Ma et al. 2020). This was caused by a southward movement of the subtropical westerly jet, which led to stronger warm advection anomalies and caused an anomalous ascending motion over CA (Peng et al. 2018; Meng et al. 2021). The wetting trend during summer in CA was associated with a deepening of anomalous cyclones in $\mathrm{CA}$, which was influenced by the 
(a) Precipitation

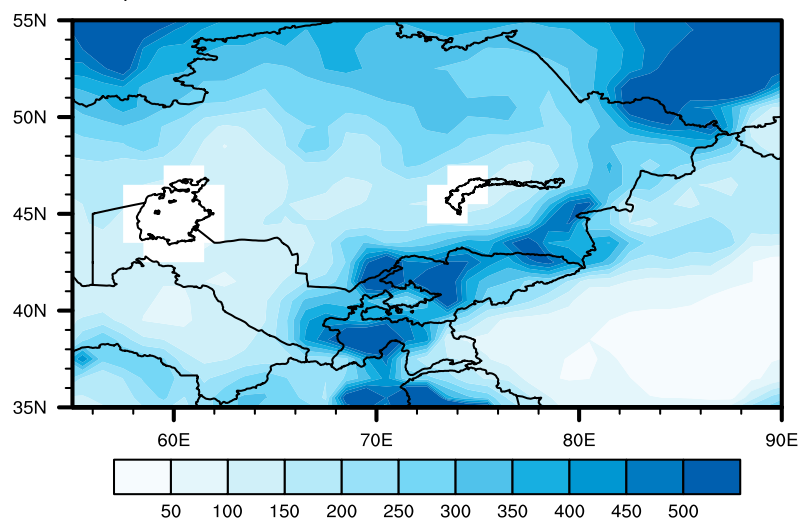

(c) Surface soil moisture content

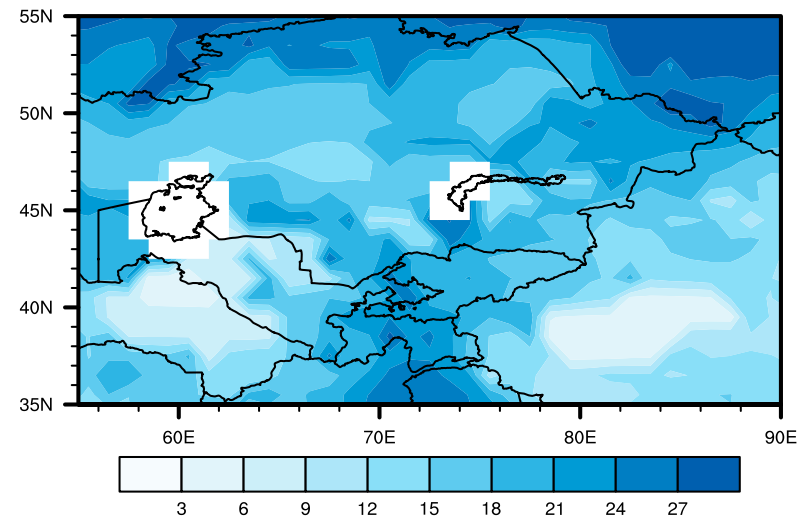

(b) Evapotranspiration

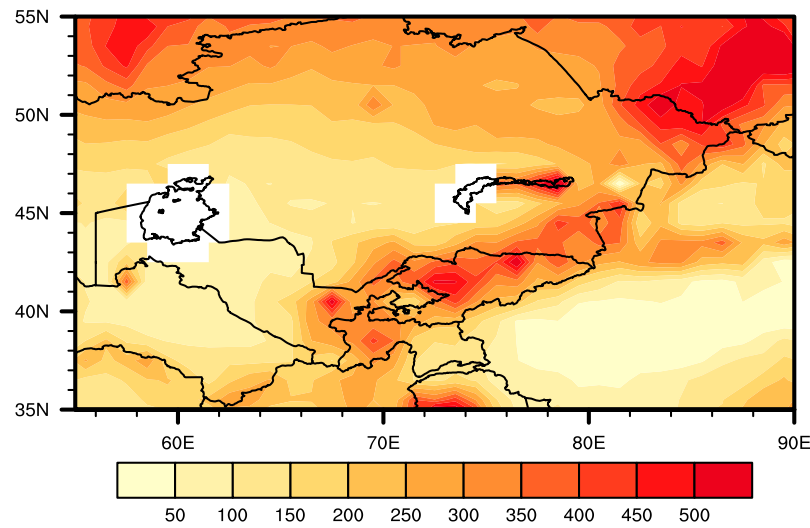

(d) $\mathrm{Al}$

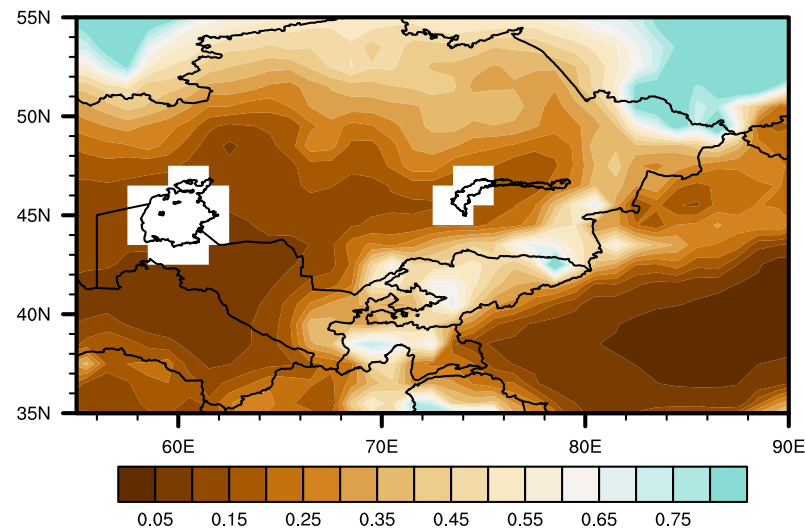

FIG. 1. Mean annual (a) precipitation $\left(\mathrm{mm} \mathrm{yr}^{-1}\right)$ based on the Global Precipitation Climatology Centre (GPCC) dataset, (b) evapotranspiration $\left(\mathrm{mm} \mathrm{yr}^{-1}\right)$ based on the Global Land Evaporation Amsterdam Model (GLEAM) dataset, (c) surface soil moisture content $\left(\mathrm{m}^{3} \mathrm{~m}^{-3}\right.$ ) based on Global Land Data Assimilation System (GLDAS) dataset, and (d) the aridity index (AI) based on the GPCC and GLDAS datasets for $1981-2019$ over central Asia $\left(35^{\circ}-55^{\circ} \mathrm{N}, 55^{\circ}-90^{\circ} \mathrm{E}\right)$. The area enclosed by the black solid line is used in this study.

negative phase of the east Atlantic/west Russian teleconnection pattern (EA-WR) (Ma et al. 2020). The positive phase of the tropical Indian Ocean also plays a key role in summer precipitation over southeastern CA. The weakened South Asian monsoon and reduced summer rainfall in India further caused positive height anomalies in the Arabian Sea and India accompanied by negative height anomalies in CA (Huang et al. 2015; Meng et al. 2021). In addition, the reduced spring snow cover over the Tibetan Plateau with the northward expansion of the South Asian high caused enhanced meridional water vapor flux from the Arabian Sea and the Bay of Bengal, which is favorable for summer precipitation in CA (Zhang et al. 2021). Over the past 40 years, winter precipitation has increased prominently faster than that during summer (Chen et al. 2011; Yang et al. 2020), which is affected by multiple large-scale systems. The positive phases of EA-WR and polar Eurasian extratropical teleconnection patterns intensified moisture transport from the Arabian Sea, the northern Indian Ocean, and North Africa and enhanced surface cyclonic activities in semiarid areas of CA (Yin et al. 2014). In addition, the long-term warming of tropical Indo-
Pacific sea surface temperature (SST) led to a decrease in precipitation by forcing anticyclonic anomalies over southwestern CA (Hoell et al. 2015)

Since regional water resources are balanced by both water supply and evaporative demand; precipitation changes alone may not be able to fully capture the changes in regional dry and wet conditions. Evapotranspiration is another key component of the surface and atmospheric water cycle and, accordingly, the effect of evapotranspiration should also be considered. Several studies have focused on evapotranspiration variability and its impact on CA. Evapotranspiration in CA had a decreasing trend before 2000 and an increasing trend afterward during 2001-12 (Li et al. 2017). In Xinjiang, evapotranspiration increased from 1979 to 2013 (Su et al. 2015). Coinciding with melting glaciers that provided additional evapotranspiration (Feng et al. 2018; Wu et al. 2019), terrestrial water storage (TWS) had a decreasing trend from 2003 to 2013 in CA (Yang and Chen 2015; Deng and Chen 2017). Although vegetation is generally sparse in CA, the contribution of evapotranspiration to local precipitation is not negligible in widely distributed oases (S. Wang et al. 2016). 
Feedback between precipitation and evapotranspiration resulted in the acceleration of local precipitation recycling from the early 1980s to the early twenty-first century (Yao et al. 2020b). Studies on lakes in northern Kazakhstan also indicated that, with local evaporation exceeding precipitation, the shrinkage of lakes in the endorheic Burabay National Park between 1986 and 2016 has been observed with a significant decline in both areal extent and volume (Yapiyev et al. 2017, 2019). Recent studies that have evaluated the changes in wet and dry conditions in CA have considered the impact of potential evapotranspiration (PET) and have used the standardized precipitation-evapotranspiration index (SPEI) as a criterion (Aralova et al. 2018; Hu et al. 2018; Ta et al. 2018). However, it should be noted that PET is different from actual evapotranspiration. By considering the influence of these factors, we attempt to identify dry and wet climatic changes in $\mathrm{CA}$ in the last four decades from a more comprehensive perspective, which considers the combined effects of precipitation and evapotranspiration.

The regional relationship between precipitation and evapotranspiration can be approximated by the Budyko framework (Budyko 1974; Fu 1981; Choudhury 1999; Roderick et al. 2014). Based on this framework, by combining the elasticity method, Budyko equations have been widely developed to estimate the contribution of regional variations in catchment characteristics/human activities and climate change to runoff, streamflow, or evapotranspiration changes (Roderick and Farquhar 2011; Wang and Hejazi 2011; Xu et al. 2014; W. Wang et al. 2016; Wu et al. 2017; Tian et al. 2018; Li et al. 2020; Gao et al. 2020). By utilizing Budyko equations in CA, we aim to acquire a better understanding of the contributions of climate change to wet/dry trends from the perspective of the surface water balance.

In addition to the surface water budget, the atmospheric water budget is another important aspect for measuring dry and wet changes. Dominguez et al. (2006) derived the dynamic precipitation recycling model (DRM), which is a method based on the conservation of the atmospheric water vapor mass that enables the precipitation recycling ratio and the origins of moisture to be calculated on an hourly time scale. The advantage of the DRM is that it includes the moisture storage term. This model has been widely used in previous studies on land-atmosphere interactions and the water cycle to analyze precipitation recycling processes in many regions (Dominguez et al. 2006; Bisselink and Dolman 2008; Hua et al. 2016, 2017). The DRM detects changes in the amount of water vapor contained in a unit area of a column of air, which undergoes multiple processes of absorbing and releasing moisture along the trajectory of moisture transmission. Therefore, the quantitative contributions from moisturesource regions to precipitation in CA can be identified. Peng et al. (2020) employed the FLEXPART model to track the source of moisture over 2011-19, and indicated that moisture from CA and Eurasia played a key role in local precipitation. The Eulerian source-tagging method implemented in the Community Atmosphere Model version 5 (CAM5) has also been used to identify the long-term trend of the moisture sources in CA during 1956-2005 (Jiang et al. 2020a).
However, studies on the quantitative contribution of recycled moisture and advected moisture to the CA precipitation variation in the last four decades are scarce. Combined with dynamic analysis of atmospheric circulation, we can discuss dry and wet climatic changes from the perspective of the atmospheric moisture budget.

Therefore, regional changes in hydrological conditions in $\mathrm{CA}$ can be assessed comprehensively, combining the surface water balance (Roderick et al. 2014) and atmospheric water balance (Dominguez et al. 2006) to identify the impact of climate change on wet/dry trends. The role of precipitation minus evapotranspiration $(P-E)$ as a bridge connecting the two balances has been investigated to quantitatively estimate and attribute dry and wet climatic changes in CA. The $P-E$ term refers to the rate of production of local water resources, generally used as an informative indicator of water conditions for oceans and land (Held and Soden 2006; Zhang and Sun 2012; Roderick et al. 2014; Y.-S. Zhou et al. 2019), which is more comprehensive than previous studies of climate change in central Asia.

In this study, we aim to answer the following questions: 1) What are the wetting and drying trends in CA, and which factors are the main contributors to changes in wet and dry conditions? 2) Which moisture source regions have contributed to the drying and wetting trends in CA? This paper is organized as follows. In section 2, we introduce the reanalysis datasets, the Budyko-Penman budget equation, the dynamic precipitation recycling model, and the moisture-source tracking method. The evaluation of reanalysis datasets is shown in section 3. In section 4, we show the detection of wet/dry trends in CA. Sections 5 and 6 discuss the attribution of the changes from the perspective of land water balance and atmospheric water balance, respectively. The conclusions and discussion are given in section 7 .

\section{Data and methods}

\section{a. Data description}

\section{1) REANALYSIS DATASETS}

Reanalysis datasets used in this study include the following:

(i) The Japanese 55-year Reanalysis (JRA-55) is maintained by the Japan Meteorology Agency's (JMA) operational data assimilation and numerical weather model (Kobayashi et al. 2015). JRA-55 has a resolution of $1.25^{\circ} \times 1.25^{\circ}$, covering the period from 1958 to the present.

(ii) The monthly precipitation and evapotranspiration dataset provided by the fifth generation of the European Centre for Medium-Range Weather Forecasts (ECMWF) reanalysis (ERA5), having a spatial resolution of $0.25^{\circ} \times 0.25^{\circ}$ from 1979 to the present.

(iii) The Modern-Era Retrospective Analysis for Research and Applications, version 2 (MERRA-2) (Gelaro et al. 2017). This dataset is released by the NASA Global Modeling and Assimilation Office, providing products with a long-term period from 1980 to the present on a $0.625^{\circ} \times 1.25^{\circ}$ horizontal resolution. 


\section{2) Precipitation datasets}

Three sets of monthly gauge-based precipitation datasets were used in this study:

(i) Monthly mean precipitation Climate Research Unit (CRU) time series version 4.0.3. This dataset was derived from the interpolation of worldwide station data, covering the period from 1901 to 2018, having a $0.5^{\circ} \times 0.5^{\circ}$ spatial resolution.

(ii) The National Oceanic and Atmospheric Administration (NOAA) Precipitation Reconstruction over Land (PREC/L) dataset spans 1948 to the present day, having a $0.5^{\circ} \times 0.5^{\circ}$ resolution.

(iii) The Global Precipitation Climatology Centre (GPCC) Full Data Reanalysis full version of 2018 (1891-2016) and version 6 (from 2017 through the present) consist of monthly land surface precipitation data covering the period from January 1891 to the present. GPCC is based on both real-time (e.g., "First Guess Monthly" and "First Guess Daily") rain gauge data as well as non-real-time (e.g., "Full Data Monthly" and "Climatology") sets of data, which is $1.0^{\circ} \times$ $1.0^{\circ}$ horizontal resolution (Becker et al. 2013).

\section{3) EVAPOTRANSPIRATION DATASETS}

By comparing the following three evapotranspiration datasets with the reanalyses, we selected the best performing reanalysis data of evapotranspiration.

(i) The Penman-Monteith-Leuning version 2 (PML_V2) global evapotranspiration and gross primary production dataset provided coupled global evapotranspiration with 8-day temporal and 500-m spatial resolutions and spanning July 2002-December 2017, which is calibrated against 8day measurements at 95 widely distributed flux towers for 10 plant functional types (Y. Zhang et al. 2019).

(ii) The surface energy balance-based global land evapotranspiration (EB-ET) dataset records monthly evapotranspiration of the global land surface obtained using satellite data and the Surface Energy Balance System (SEBS) (Chen et al. 2013, 2019). This dataset has a spatial resolution of $5 \mathrm{~km} \times 5 \mathrm{~km}$, covering the period from 2000 to 2017.

(iii) Version 3 of the Global Land Evaporation Amsterdam Model (GLEAM v3) provides terrestrial evapotranspiration on a $0.25^{\circ} \times 0.25^{\circ}$ latitude-longitude grid, having a monthly temporal resolution spanning 1980-2018 (Martens et al. 2017).

\section{4) OTHER DATASETS}

(i) The Extended Reconstructed Sea Surface Temperature (ERSST) for 1982-2019 is obtained from the International Comprehensive Ocean-Atmosphere Dataset (ICOADS). The dataset is on a $1^{\circ} \times 1^{\circ}$ latitude-longitude grid.

(ii) The surface soil moisture content $\left(\mathrm{m}^{3} \mathrm{~m}^{-3}\right)$ is provided by the Global Land Data Assimilation System (GLDAS) dataset on a $1^{\circ} \times 1^{\circ}$ latitude-longitude grid, having a monthly temporal resolution spanning from 1948 to 2014 .

(iii) The third-generation normalized difference vegetation index (NDVI) is obtained from the Global Inventory Monitoring and Modeling System (GIMMS) on a $1 / 12^{\circ} \times$ $1 / 12^{\circ}$ latitude-longitude grid, covering the period from 1982 to 2015.

\section{b. Method description}

\section{1) BUDYKO-PENMAN BUDGET DESCRIPTION}

Budyko's hypothesis is the most general statistical approach relating to $E$ and $P$ on land (Budyko 1974). This hypothesis describes the dependence of evapotranspiration on the energy supply (usually represented by potential evapotranspiration) and water supply (usually measured by precipitation) (Fu 1981; Roderick and Farquhar 2011; Roderick et al. 2014). The equation that is widely used for this hypothesis was proposed by Choudhury (1999), as

$$
E=\frac{E_{0} P}{\left(P^{n}+E_{0}^{n}\right)^{1 / n}},
$$

where $P, E_{0}, E$, and $n$ are precipitation, potential evapotranspiration, actual evapotranspiration, and catchment properties parameters, respectively; $n$ represents the effect of soil condition, vegetation, and topography changes.

Another widely used equation for Budyko's hypothesis is derived from $\mathrm{Fu}(1981)$ as

$$
E=P+E_{0}-\left(P^{\omega}+E_{o}^{\omega}\right)^{1 / \omega}
$$

where $\omega$ performs a similar role to $n$ in Eq. (1).

By using Fu's method with Choudhury's equation [Eq. (1)], Yang et al. (2008) found that the two catchment property parameters have a linear relationship, as

$$
\omega=n+0.72
$$

where there exists a linear relationship between $\omega$ and the climatological normalized difference vegetation index [Eq. (4)] (Weier and Herring 2000; Li et al. 2013):

$$
\begin{gathered}
\mathrm{NDVI}=\frac{(\mathrm{NIR}-\mathrm{VIS})}{(\mathrm{NIR}+\mathrm{VIS})}, \\
\omega=2.36\left(\frac{\mathrm{NDVI}^{-} \mathrm{NDVI}_{\min }}{\mathrm{NDVI}_{\text {max }}-\mathrm{NDVI}_{\min }}\right)+1.16 .
\end{gathered}
$$

In Eq. (4), VIS and NIR stand for the spectral reflectance measurements acquired in the visible and near-infrared bands, respectively. The NDVI index can be used to quantify the density of plant growth. In Eq. (5), NDVI min and $\mathrm{NDVI}_{\text {max }}$ represent the maximum and minimum values of NDVI during the given period, respectively. Therefore, parameter $n$ can be obtained by calculating NDVI. Since our research period is relatively short, we do not consider the change of $n(d n=0)$ (Roderick et al. 2014). Under this 
assumption, the total differential of $P-E$ can be shown as

$$
d(P-E)=\left(1-\frac{\partial E}{\partial P}\right) d P-\frac{\partial E}{\partial E_{0}} d E_{0}
$$

where $E_{0}$ can be calculated using the Penman-Monteith (P-M) equation recommended by the Food and Agriculture Organization (FAO) (Allen et al. 1998):

$$
E_{0}=\frac{\left[\left(R_{n}-G\right) \Delta\left(T_{a}\right)+\rho_{a} C_{p} D C_{H}|u|\right]}{\left[\Delta\left(T_{a}\right)+\gamma\left(1+r_{s} C_{H}|u|\right)\right]} / L_{v},
$$

where $R_{n}\left(\mathrm{MJ} \mathrm{m}^{-2}\right.$ day $\left.^{-1}\right)$ is net surface radiation; $G\left(\mathrm{MJ} \mathrm{m}^{-2}\right.$ day $^{-1}$ ) is the heat flux into the ground; $T_{a}(\mathrm{~K})$ is air temperature at 2-m height; $D(\mathrm{~Pa})$ is saturated water pressure deficit; $u\left(\mathrm{~m} \mathrm{~s}^{-1}\right)$ is wind speed at 2-m height; $\gamma\left(\mathrm{Pa} \mathrm{K}^{-1}\right)$ is the psychometric constant; $\rho_{a}\left(\mathrm{~kg} \mathrm{~m}^{-3}\right)$ is air density; $C_{p}\left(\mathrm{~J} \mathrm{~kg}^{-1} \mathrm{~K}^{-1}\right)$ is specific heat of air at a constant pressure; $\Delta\left(T_{a}\right)\left(\mathrm{Pa} \mathrm{K}^{-1}\right)$ is the slope of the saturated water pressure with respect to temperature; $L_{v}\left(\mathrm{MJ} \mathrm{kg}^{-1}\right)$ is the latent heat of vaporization of water; $r_{S}\left(\mathrm{~s} \mathrm{~m}^{-1}\right)$ is surface resistance; and $C_{H}$ is the bulk transfer coefficient.

As $E_{0}$ is a function of $T_{a}, D, u$, and $R_{n}-G$, the contributions of $T_{a}, D, u$, and $R_{n}-G$ to $E_{0}$ changes can be approximated as

$d E_{0} \approx \frac{\partial E_{0}}{\partial\left(R_{n}-G\right)} d\left(R_{n}-G\right)+\frac{\partial E_{0}}{\partial T_{a}} d T_{a}+\frac{\partial E_{0}}{\partial u} d u+\frac{\partial E_{0}}{\partial D} d D$.

By substituting Eq. (6) into Eq. (8), the contributions of various factors to changes in $P-E$ can be calculated as

$$
\begin{aligned}
d(P-E) \approx & \frac{\partial(P-E)}{\partial P} d P+\frac{\partial(P-E)}{\partial\left(R_{n}-G\right)} d\left(R_{n}-G\right) \\
& +\frac{\partial(P-E)}{\partial T_{a}} d T_{a}+\frac{\partial(P-E)}{\partial u} d u+\frac{\partial(P-E)}{\partial D} d D
\end{aligned}
$$

where $d(P-E), d P, d\left(R_{n}-G\right), d T_{a}, d u$, and $d D$ are mean changes over a given period for $P-E, P, R_{n}-G, T_{a}, u$, and $D$, respectively. The terms $[\partial(P-E) / \partial P] d P,[\partial(P-E) /$ $\left.\partial\left(R_{n}-G\right)\right] d\left(R_{n}-G\right), \quad\left[\partial(P-E) / \partial T_{a}\right] d T_{a}, \quad[\partial(P-E) / \partial u] d u$, and $[\partial(P-E) / \partial D] d D$ represent the contributions to the changes in $P-E$. The relative roles of individual climate drivers to $P-E$ changes can be quantified by comparing the contributions of individual factors in Eq. (9). The partial differentials in Eq. (9) are given by

$$
\begin{gathered}
\frac{\partial(P-E)}{\partial p}=1-\frac{E}{P}\left(\frac{E_{0}^{n}}{P^{n}+E_{0}^{n}}\right), \\
\frac{\partial(P-E)}{\partial\left(R_{n}-G\right)}=(-1) \frac{E}{E_{0}}\left(\frac{P^{n}}{P^{n}+E_{0}^{n}}\right) \\
\quad \times\left\{\frac{\Delta\left(T_{a}\right)}{L_{v}\left[\Delta\left(T_{a}\right)+\gamma\left(1+r_{s} C_{H}|u|\right)\right]}\right\},
\end{gathered}
$$

$$
\begin{aligned}
\frac{\partial(P-E)}{\partial T_{a}}= & (-1) \frac{E}{E_{0}}\left(\frac{P^{n}}{P^{n}+E_{0}^{n}}\right)\left\{\frac{R_{n}-G}{L_{v}\left[\Delta\left(T_{a}\right)+\gamma\left(1+r_{s} C_{H}|u|\right)\right]}\right. \\
& \left.-\frac{\Delta\left(T_{a}\right)\left(R_{n}-G\right)+\rho_{a} C_{p} D C_{H}|u|}{L_{v}\left[\Delta\left(T_{a}\right)+\gamma\left(1+r_{s} C_{H}|u|\right)\right]^{2}}\right\} \\
& \times\left\{610.8 \times 17.27 \times 237.3 \times \exp \left[\frac{17.27\left(T_{a}-273.16\right)}{T_{a}-35.86}\right]\right. \\
& \left.\times \frac{17.27 \times 237.3-2\left(T_{a}-35.86\right)}{\left(T_{a}-35.86\right)^{4}}\right\},
\end{aligned}
$$

$$
\begin{aligned}
\frac{\partial(P-E)}{\partial u}= & (-1) \frac{E}{E_{0}}\left(\frac{P^{n}}{P^{n}+E_{0}^{n}}\right)\left\{\frac{\rho_{a} C_{p} D C_{H}}{L_{v}\left[\Delta\left(T_{a}\right)+\gamma\left(1+r_{s} C_{H}|u|\right)\right]}\right. \\
& \left.-\frac{\gamma r_{s} C_{H}\left[\left(R_{n}-G\right) \Delta\left(T_{a}\right)+\rho_{a} C_{p} D C_{H}|u|\right]}{L_{v}\left[\Delta\left(T_{a}\right)+\gamma\left(1+r_{s} C_{H}|u|\right)\right]^{2}}\right\}, \quad(10 \\
\frac{\partial(P-E)}{\partial D}= & (-1) \frac{E}{E_{0}}\left(\frac{P^{n}}{P^{n}+E_{0}^{n}}\right)\left\{\frac{\rho_{a} C_{p} D C_{H}}{L_{v}\left[\Delta\left(T_{a}\right)+\gamma\left(1+r_{s} C_{H}|u|\right)\right]}\right. \\
& \left.-\frac{\gamma r_{s} C_{H}\left[\left(R_{n}-G\right) \Delta\left(T_{a}\right)+\rho_{a} C_{p} D C_{H}|u|\right]}{L_{v}\left[\Delta\left(T_{a}\right)+\gamma\left(1+r_{s} C_{H}|u|\right)\right]^{2}}\right\}
\end{aligned}
$$

Equation (10) shows the sensitivity of individual factors to changes in $P-E$, in which each variable is the mean climatologic value.

\section{2) DRM DESCRIPTION}

The dynamic precipitation recycling model (DRM) is applied in this study to describe the regional precipitation recycling ratio variations and source of water vapor to local precipitation over CA for different seasons. The DRM is derived from the conservation of atmospheric water vapor mass:

$$
\frac{\partial W}{\partial t}+\nabla \cdot Q=E-P+\text { res }
$$

In Eq. (10), $W$ is the amount of water vapor contained in a unit area column of air; $Q$ represents the water vapor convergence and res represents the residual term.

The DRM is developed under the assumption that water vapor of local evapotranspiration and advected moisture are well mixed in the vertical direction in the atmosphere. Under this assumption, Eq. (11) was vertically integrated to derive the equation for the recycling ratio, as

$$
\frac{\partial \rho}{\partial t}+\mathbf{V} \cdot \nabla \rho=\frac{(1-\rho) E}{W},
$$

where $\rho$ and $\mathbf{V}$ are respectively the recycling ratio and water vapor velocity. The expression for local recycling ratio was calculated by integrating Eq. (11) for the moisture transmission trajectory $s$, as

$$
\rho(s)=1-\exp \left[-\int_{s_{0}}^{s}\left(\frac{E}{W}\right) d s\right],
$$


where $s_{0}$ is the original point of the moisture trajectory. The precipitation recycling ratio within the region consisting of $z$ cells was then calculated as

$$
\rho=\frac{P_{m}}{P}=\frac{\sum_{i=1}^{z} \rho_{i} P_{i} \Delta A_{i}}{\sum_{i=1}^{z} P_{i} \Delta A_{i}}
$$

\section{3) MOISTURE-SOURCE TRACKING METHOD}

To identify moisture sources of CA precipitation, we used a valid "moisture source attribution" method developed by Sodemann et al. (2008). This method considers the change of moisture in a trajectory from origins to the target area, quantifying the contribution of evapotranspiration along the trajectory to precipitation at the target area in the Lagrangian framework, which is widely applied in previous investigations (Martius et al. 2013; Sun and Wang 2014; Peng et al. 2020). It should be noted that the DRM differs from FLEXPAT as it is a two-dimensional model. Therefore, we altered Soderman's method. Soderman's method is a three-dimensional tracking method in which a large number of particles (e.g., one million) of equal mass are released to become randomly distributed in the entire global atmosphere. When reaching the target area from the moisture source regions, the moisture of an air particle may increase or decrease owing to the precipitation or evaporation processes. However, because the DRM is a two-dimensional model, we mainly use $W$ to track backward and calculate the changes of the moisture in the air column where multiple processes of absorbing and releasing water vapor occurs. Therefore, our altered version of Soderman's method consists of the following three steps:

(i) According to the results of the DRM, we identify all targetbound trajectories that have moisture released in the target area.

(ii) When reaching the target area from the moisture-uptake location, the moisture of the air column may increase or decrease because they may undergo multiple cycles of evaporation and precipitation process. Calculating $\Delta W=$ $W(t)-W(t-6 \mathrm{~h})$ by time for the $k$ th backward trajectory, the point where $\Delta W>0$ is recorded for the first time is defined as the starting point for the tracking.

In regions where $\Delta W>0$, evapotranspiration in this location results in the whole air column removing moisture from the area. The fractional contribution $\left(f_{n}\right)$ of $\Delta W$ to the moisture in a unit area air column $\left(W_{n}\right)$ in that moment $n$ is shown as

$$
f_{n}^{k}=\frac{\Delta W_{n}^{k}}{W_{n}^{k}}
$$

When moving toward the target area, the air column undergoes multiple processes of absorbing and releasing water vapor. New moisture uptake reduces the contribution of previous uptakes, and the moisture contribution at previous times $(\mathrm{m})$ should be updated as

$$
f_{m}^{k}=\frac{\Delta W_{m}^{k}}{W_{n}^{k}}, \quad m<n,
$$

where $f_{m}$ is the fractional contributions of all moisture uptakes at previous times $m$ with respect to new moisture in a unit area air column in the moment $n$.

When $\Delta W<0$, precipitation results in the whole air column releasing moisture at that location, therefore also reducing all previous contributions of $\Delta W$ to moisture in a unit area air column. Thus, moisture uptake $\Delta W$ is discounted in proportion to precipitation, as

$$
\Delta W_{m}^{k^{\prime}}=\Delta W_{m}^{k}+\Delta W_{n}^{k} f_{m}^{k}, \quad \text { for all } m<n
$$

When the air column reaches the target region, the sum of the latest fractional contributions of all uptake points constitutes the total contribution of all points on the trajectory during the entire period of time. One trajectory can determine some moisture origins, and the contribution of water vapor origin to precipitation is dominated by the sum of all trajectories (Peng et al. 2020).

(iii) The contribution percentage of the $j$ th moisture source region to $\mathrm{CA}$ precipitation is calculated as

$$
\mathrm{CP}_{j}=\frac{\sum_{k=1}^{k_{\text {tot }}} \Delta W^{k}(j)}{\sum_{k=1}^{k_{\text {tot }}} W_{t=-6 \mathrm{~h}}} \times 100 \%,
$$

where $\mathrm{CP}$ is the sum of the contributions of all trajectories for the $j$ th moisture source region.

\section{4) Cumulative AnOmaly test}

To determine the interdecadal transition, the cumulative anomalies were calculated (Sun et al. 2020). The formula is

$$
\hat{x}_{t}=\sum_{i=1}^{t}\left(x_{i}-\bar{x}\right), \quad(t=1,2,3, \ldots, l),
$$

where $x_{i}(1,2,3, \ldots, l), \bar{x}, l$, and $\hat{x}_{t}$ are the original time series, the average over a period, the length of time, and the cumulative anomaly at time $t$, respectively.

In addition, significance testing was performed using Student's $t$ test method for differences and regression coefficients on interdecadal time scales.

\section{Evaluation of reanalysis datasets}

To produce results with higher reliability, multiple reanalysis datasets were compared to identify the dataset with the closest agreement with the observations. Detailed comparisons indicate that $E$ and $P$ generally exhibit large fluctuations from 1982 to 2019 in all six datasets (Figs. 2a,b). The trends of $E$ exhibited in MERRA-2 [54.3 mm (38 yr) ${ }^{-1} ; p<0.01$ ], GLEAM [40.4 mm (38 yr $\left.)^{-1}, p<0.01\right]$, and JRA-55 [26.0 $\left.\mathrm{mm}(38 \mathrm{yr})^{-1} ; p<0.05\right]$ were much stronger and more significant than those in the other $E$ datasets (Fig. 2a). GLEAM is suitably and widely used for global changes in hydrological conditions (e.g., trend, time series, and spatial analyses) (Miralles et al. 2013; Greve et al. 2014; Martens et al. 2018). Therefore, 
(a)
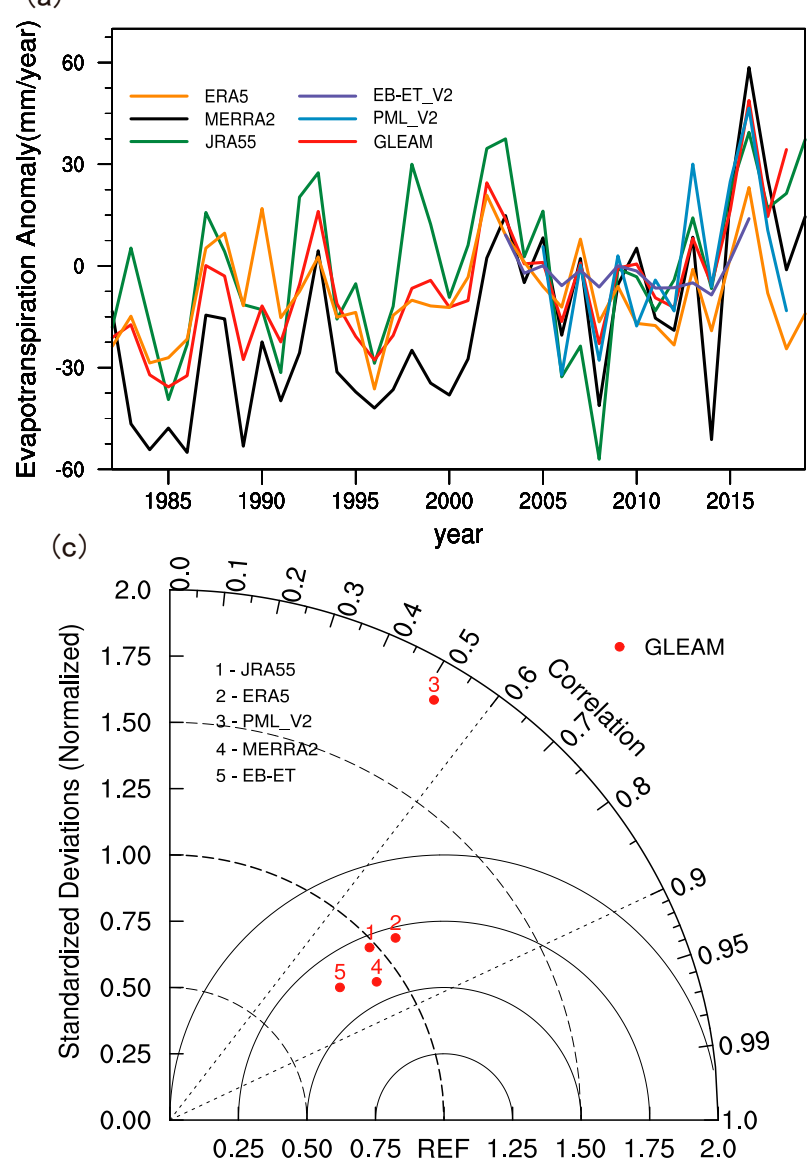

(e)

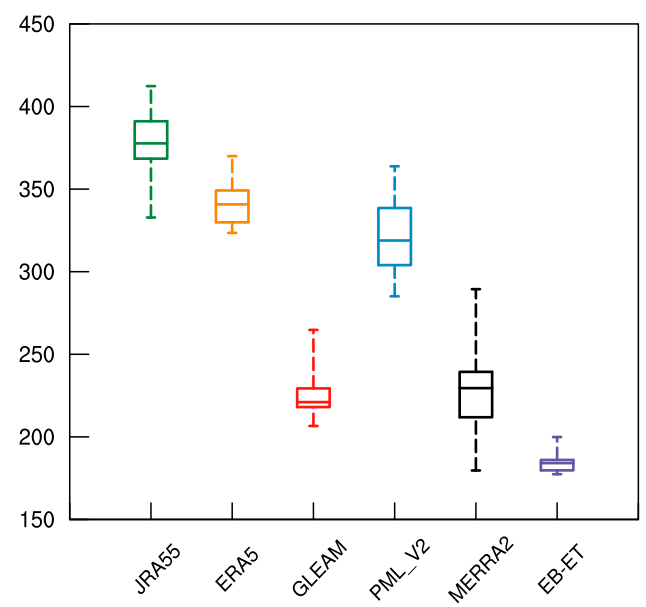

(b)
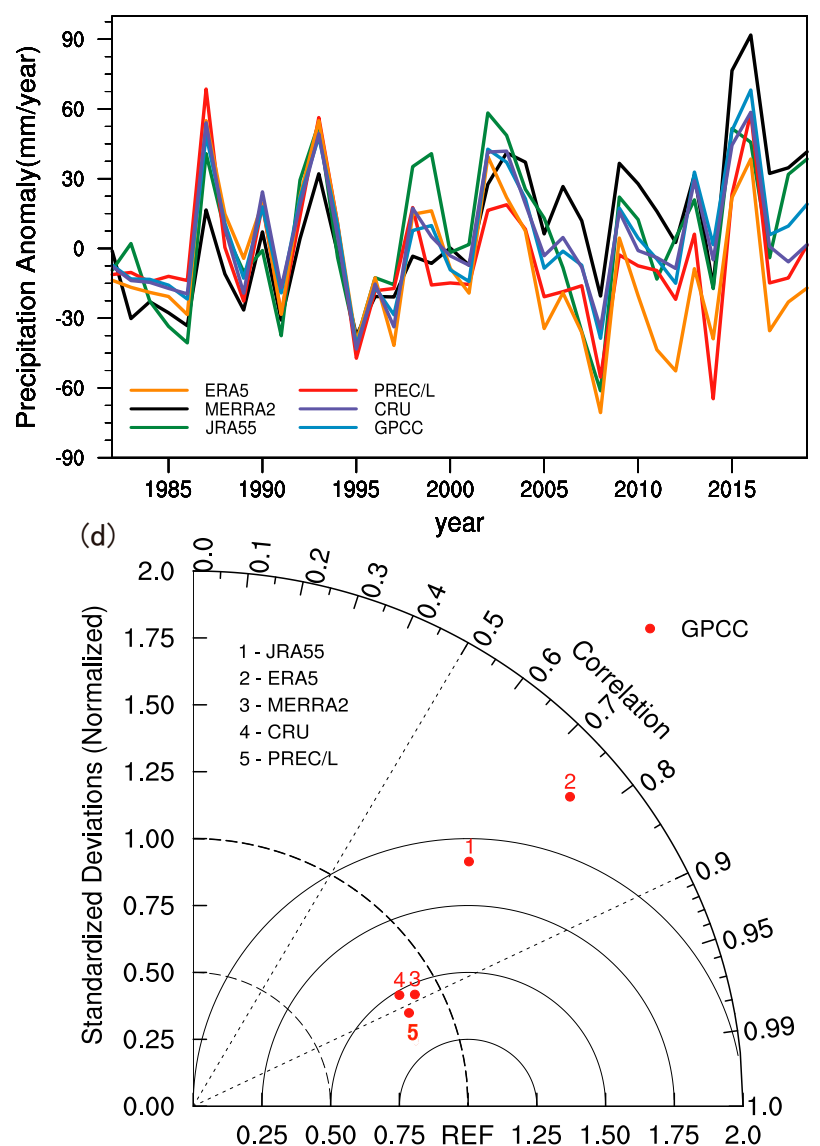

(f)

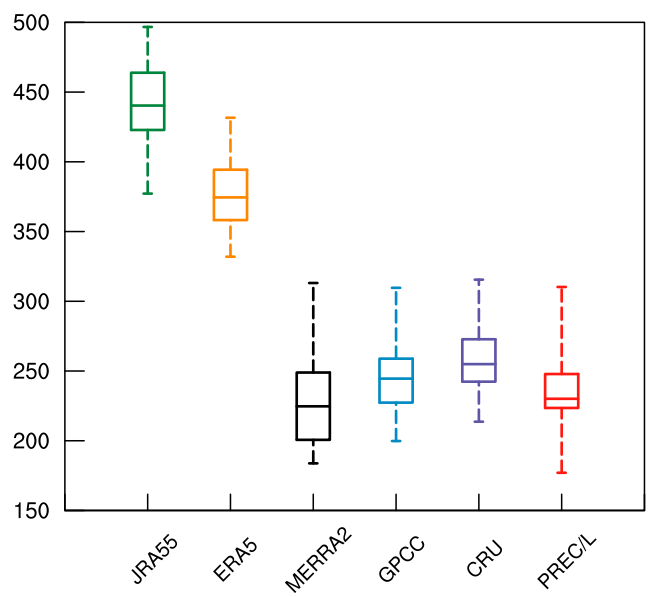

FIG. 2. Intercomparison of six datasets of precipitation and evapotranspiration obtained from GLEAM, CPC, CRU, MERRA-2, GPCC,

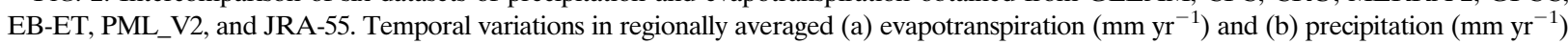
over CA from 1982 to 2019. (c) Taylor diagrams of each evapotranspiration data, with GLEAM as a reference. (d) Taylor diagrams of each precipitation data, with GPCC as a reference. Also shown are the statistical distributions of area-averaged annual mean (e) evapotranspiration $\left(\mathrm{mm} \mathrm{yr}^{-1}\right)$ calculated from 2003 to 2016 and (f) precipitation $\left(\mathrm{mm} \mathrm{yr}^{-1}\right)$ calculated from 1982 to 2019. 
(a)
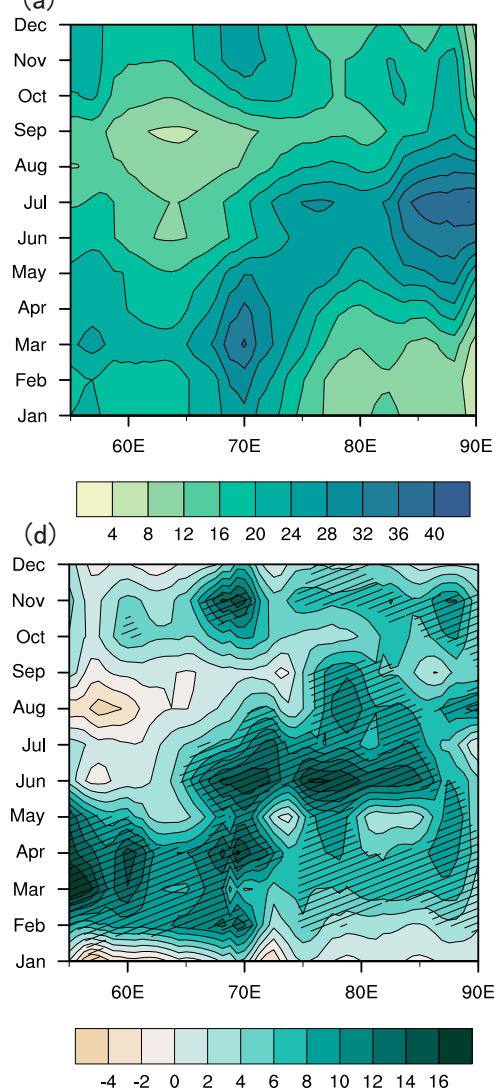

(b)

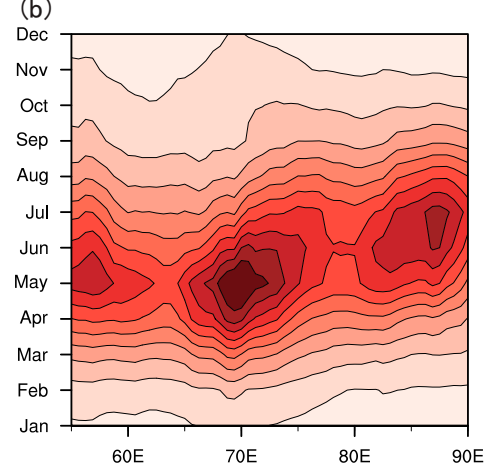

(e)
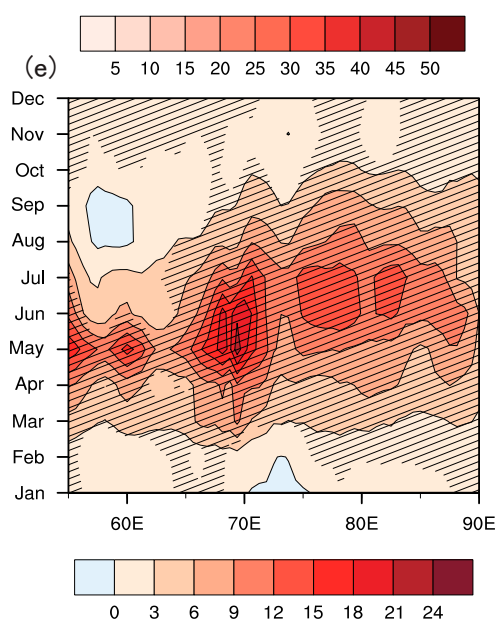

(c)
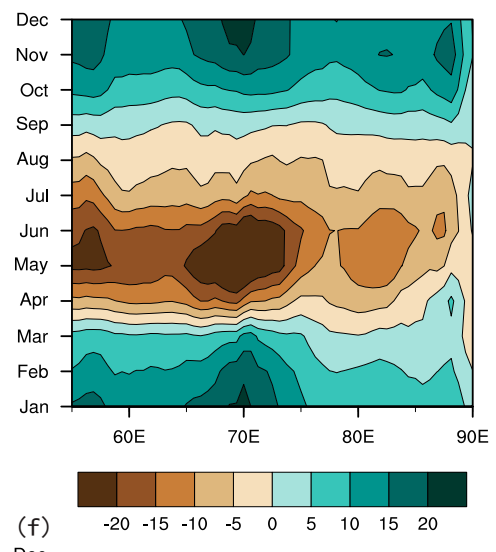

Dec

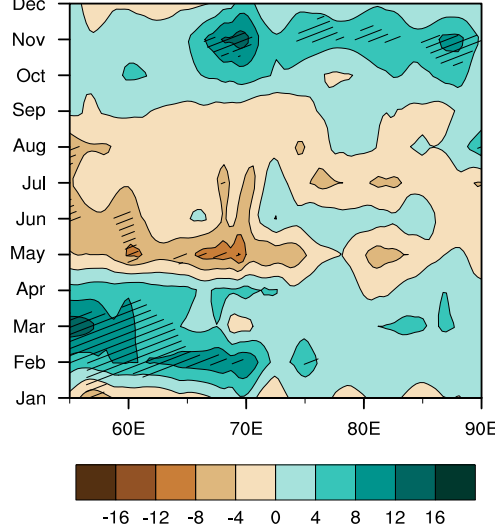

FIG. 3. The meridional mean (a)-(c) climatology [mm $\left.(6 \text { months })^{-1}\right]$ and (d)-(f) 38 -yr changes $\left[\mathrm{mm}\left(6(\mathrm{months})^{-1}(38 \mathrm{yr})^{-1}\right]\right.$ in the (left) $P$, (middle) $E$, and (right) $P-E$ over CA during 1982-2019. The black shaded slash indicates that the changes are significant at the 0.1 level. The latitudinal range for meridional mean is $35^{\circ}-50^{\circ} \mathrm{N}$.

we selected GLEAM as the reference in the Taylor diagram. The correlation coefficients of GLEAM and JRA-55, ERA5, MERRA2, PML_V2, and EB-ET are 0.746, 0.768, 0.823, 0.519, and 0.778 , respectively. The standard deviations of GLEAM and JRA-55, ERA5, MERRA2, PML_V2, and EB-ET are $0.977,1.072,0.916,1.854$, and 0.797 , respectively. Although the standard deviation of MERRA2 is slightly larger than that of EB-ET, MERRA-2 has the strongest correlation (0.823) with GLEAM (Fig. 2c). Moreover, the statistical distribution of the area-average annual mean $E$ obtained from the GLEAM JRA55, ERA5, MERRA2, PML_V2, and EB-ET datasets also record large differences, with the medians being 221.05, 377.68, $340.77,229.51,318.88$, and $184.12 \mathrm{~mm} \mathrm{yr}^{-1}$, respectively, in which MERRA-2 is in good agreement with GLEAM (Fig. 2e). Between 1982 and 2019, the results for precipitation record fluctuations that are greater than those of $E$, with no obvious trends for CRU, CPC, and ERA5. GPCC has a significant increasing trend of $23.5 \mathrm{~mm}(38 \mathrm{yr})^{-1}(p<0.1)$, which is similar to MERRA2 and JRA-55 (Fig. 2b). Considering that the gridded GPCC datasets have fused the largest number of gaugeobservation datasets from more than 70000 different stations and the capacity to qualitatively identify wet and dry years in southwestern Asia on a regional scale (Schiemann et al. 2008; Hoell et al. 2015), we selected GPCC as the reference object in the Taylor diagram for precipitation (Fig. 2d). The correlation coefficients of GPCC and JRA-55, ERA5, MERRA2, CRU, and PREC/L are $0.739,0.764,0.888,0.875$, and 0.914 , respectively. The standardized deviations of GPCC and JRA-55, ERA5, MERRA2, CRU, and PREC/L are 1.357, 1.793, 0.908, 0.857 , and 0.859 , respectively. Precipitation from MERRA-2 has the highest correlation and the minimum deviation with GPCC among the three reanalysis datasets, and they exhibit similar variability (Figs. 2b,d). In terms of median amount, GPCC, CRU, PREC/L, and MERRA2 all perform similarly, which are $244.54,254.93,230.09$, and $224.69 \mathrm{~mm} \mathrm{yr}^{-1}$, respectively. However, the values of JRA-55 and ERA5 are higher, 440.33 and 374.48 (Fig. 2f). As seen from the above results, $E$ and $P$ from MERRA-2 adequately capture the characteristics of satellite and observation data. Thus, we selected MERRA-2 from 1982 to 2019 for analysis and calculation among the three reanalysis datasets.

\section{Wetness/dryness changes}

Dry and wet climatic trends in CA over the past four decades were examined. The climatological annual meridional mean and trends of $P, E$, and $P-E$ are shown in Fig. 3. The meridional mean monthly $P$ in $\mathrm{CA}$ ranges from less than 
(a) Wet seaon 38-year changes in P during 1982-2019

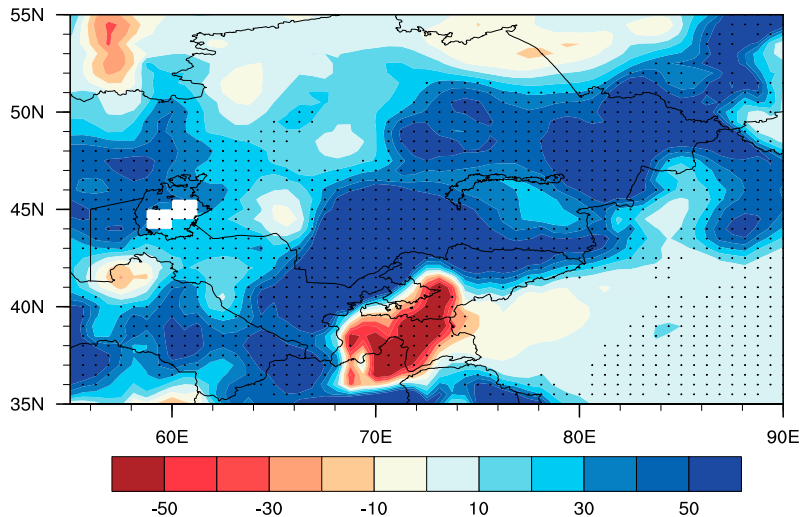

(c) Wet seaon 38-year changes in E during 1982-2019

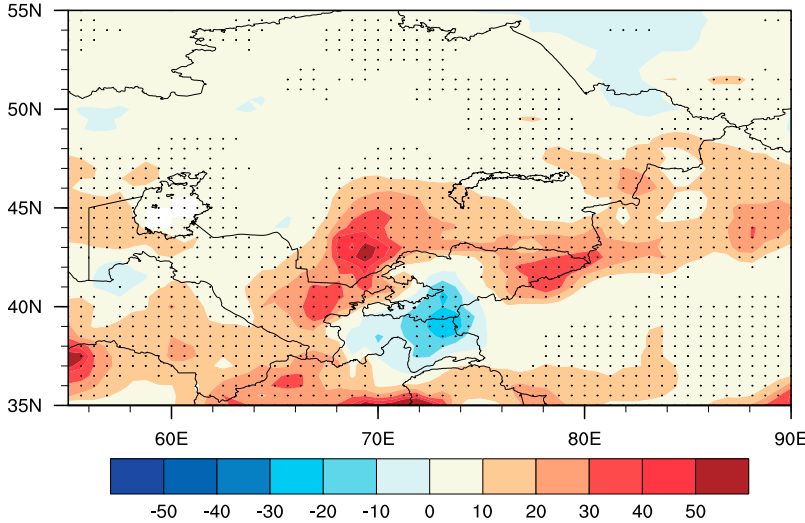

(e) Wet seaon 38-year changes in P-E during 1982-2019

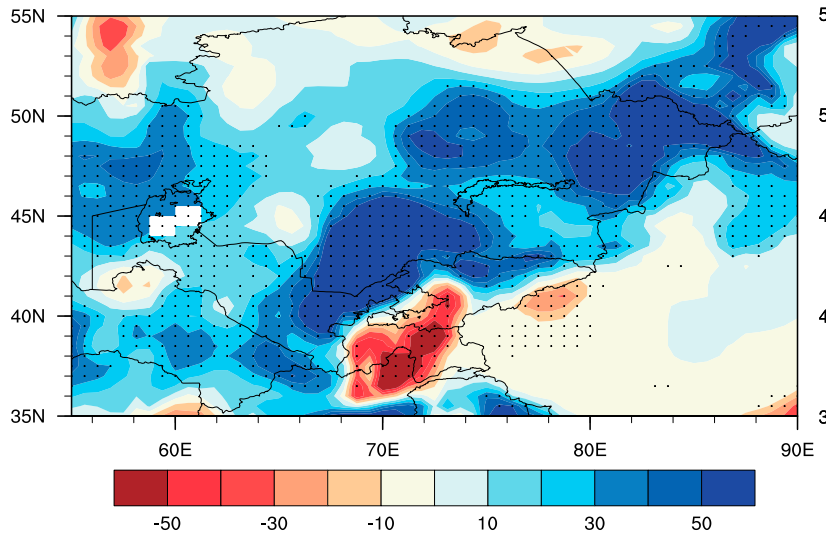

(b) Dry seaon 38-year changes in P during 1982-2019

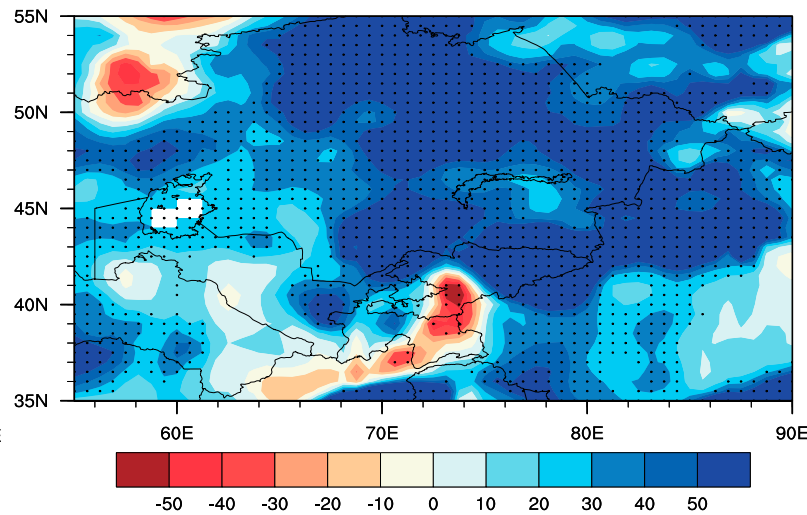

(d) Dry seaon 38-year changes in E during 1982-2019

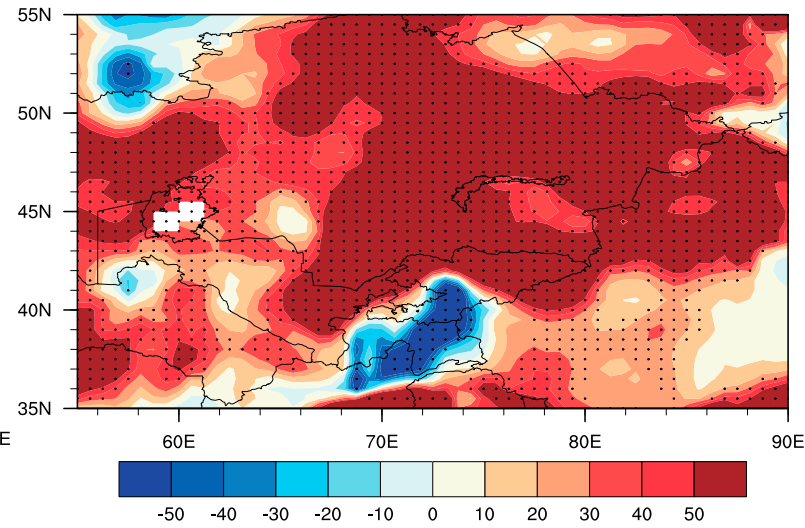

(f) Dry seaon 38-year changes in P-E during 1982-2019

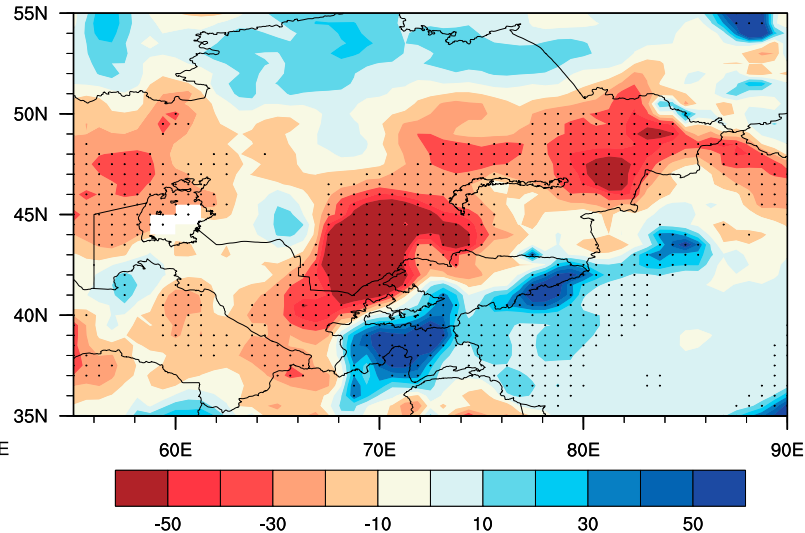

FIG. 4. (left) Wet and (right) dry season 38 -yr changes in (a),(b), $P$ (c),(d) $E$, and (e),(f) $P-E\left[\mathrm{~mm}(6 \mathrm{months})^{-1}(38 \mathrm{yr})^{-1}\right]$ for 1982-2019 over CA. The dots indicate changes over CA in (a)-(f) are statistically significant at the 0.1 level.

$4 \mathrm{~mm}$ to greater than $40 \mathrm{~mm}$. With $72^{\circ} \mathrm{E}$ as the demarcation line, $P$ over western CA is relatively large from November to April; over eastern CA, it is higher from May to October (Fig. 3a). Studies have suggested that if the wet and dry seasons are defined in terms of precipitation, the periods of dry and wet seasons are opposite for western and eastern CA (Peng et al. 2020). We used the least squares method to calculate the linear changes of each variable during 1982-2019. Notably, $P$ exhibits a significant increase in almost all months for the 38 years, except for July-September in western CA (Figs. 3d and 4a,b). The meridional mean monthly total $E$ ranges from less than $5 \mathrm{~mm}$ to greater than $50 \mathrm{~mm}$. Unlike $P, E$ is mainly higher from April to July (Fig. $3 b)$; the 38 -yr positive changes in $E$ are found in almost all 

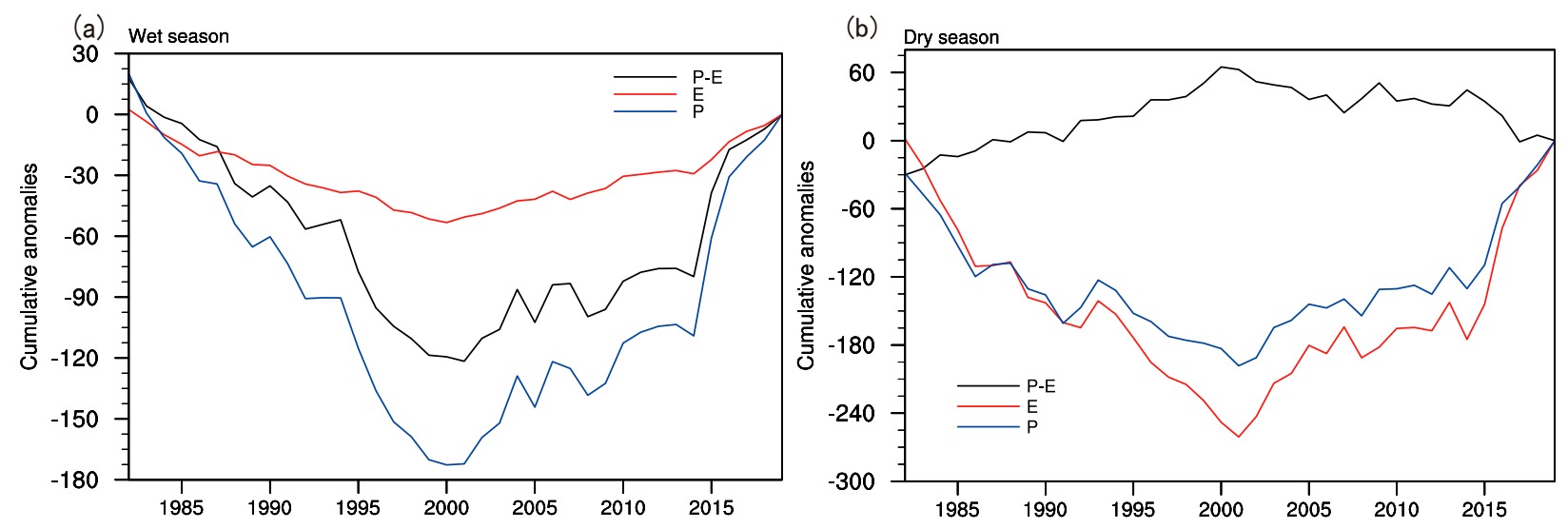

FIG. 5. Cumulative anomalies of $P, E$, and $P-E\left[\mathrm{~mm}(6 \text { months })^{-1}\right]$ during 1982-2019 in (a) the wet season and (b) the dry season.

months, with a peak concentrated in May-July (Figs. 3e and 4c,d). The distribution of $P-E$ is seasonal, with $P-E<0$ from April to September and $P-E>0$ from October to March (Fig. 3c). Therefore, based on $P-E$, we defined April-September as the dry season and October-March as the wet season. In CA, the dry season became drier and the wet season became wetter based on the 38-yr changes in $P-E$ (Fig. 3f). It should be noted that the changes in the meridional mean $P-E$ did not pass the significance test due to opposite changes in Xinjiang and eastern Kazakhstan $\left(45^{\circ}-52^{\circ} \mathrm{N}, 72^{\circ}-90^{\circ} \mathrm{E}\right)$ : the former is positive (negative) but the latter is negative (positive) in the dry (wet) season (Figs. 4e,f). These two opposing changes are offset in the meridional mean, which leads to insignificant dry/wet changes in eastern CA (Fig. 3f). From the spatial 38-yr changes in $P-E$ (Figs. $4 \mathrm{e}, \mathrm{f})$, the phenomenon of the dry season getting drier and wet season getting wetter is evident.

To assess how the change in $P-E$ in different seasons dominates the dry and wet climatic changes, we calculated the cumulative anomalies to determine the interannual and decadal variability in $P-E$. During the wet season, cumulative anomalies of $P, E$, and $P-E$ record a downward trend before 2001 and an upward trend afterward, indicating that an obvious decadal variation in $P-E$ occurred in approximately 2001 (Fig. 5a). Cumulative anomalies of $P-E$ in the dry season records an increasing trend before 2000 and a decreasing trend afterward (Fig. 5b), while $E$ and $P$ are the opposite to $P-E$, and the multidecadal variability of $E$ is of greater magnitude than that of $P$. Therefore, we divided the study period into two periods: 1982-2000 and 2001-19. Based on the above analysis of the interdecadal average $P, E$, and $P-E$, the corresponding surface water budget was analyzed to reveal the underlying mechanism responsible for the changes.

\section{Surface water budget analysis}

By considering seasonal and regional results gained for $P-E$, the Budyko-Penman budget based on the surface water balance was studied separately in the dry and wet seasons. The area-averaged Budyko-Penman budget com- ponents of $P-E$ are shown in Fig. 6. During the wet season, the magnitude of changes in $P-E$ between 2001-19 and 1982-2000 directly calculated by MERRA-2 was $12.57 \mathrm{~mm}$ (6 months $)^{-1}(p<0.01)$, and the sum of the climate factors obtained by decomposition was $13.29 \mathrm{~mm}$ (6 months $)^{-1}$, having small differences between the two results. By far $P$ had the largest positive contribution to the wetting trend (12.87 $\mathrm{mm} 6$ month $\left.^{-1} ; 96.84 \%\right)$, followed by $D[0.30 \mathrm{~mm}$ (6 months $\left.)^{-1} ; 2.26 \%\right], R_{n}-G\left[0.09 \mathrm{~mm}(6 \text { months })^{-1}\right.$; $0.70 \%], U\left[0.06 \mathrm{~mm}(6 \text { months })^{-1} ; 0.47 \%\right]$, and $T_{a}[-0.04 \mathrm{~mm}$ (6 months $\left.)^{-1} ;-0.31 \%\right]$ (Fig. 6a). Although the contribution of $E_{0}$ was positive, it was notably less than that of precipitation. For the dry season, the magnitude of changes in $P-E$ between 2001-19 and 1982-2000 calculated directly by MERRA-2 was $-6.83 \mathrm{~mm}(6 \text { months })^{-1}(p<0.1)$, and the sum of the contribution of the climatic factors obtained by decomposition was $-5.69 \mathrm{~mm}$ (6 months $)^{-1}$. The impacts of individual climatic factors on $P-E$ change were $P[-5.43$ $\left.\mathrm{mm}(6 \mathrm{months})^{-1} ; 95.43 \%\right], R_{n}-G\left[-0.20 \mathrm{~mm}(6 \text { months })^{-1}\right.$; $3.51 \%$ ], $D$ [0.15 mm (6 months $)^{-1} ;-2.64 \%$ ], $T_{a}[-0.12 \mathrm{~mm}$ (6 months $\left.)^{-1} ; 2.11 \%\right]$, and $U\left[-0.08 \mathrm{~mm}(6 \text { months })^{-1}\right.$; $1.41 \%$ ] (Fig. 6b). During the 38-yr period, $P-E$ in the wet season had a trend of initially decreasing before increasing (Fig. 6c). In contrast, $P-E$ had a slight initial increase before having a downward trend in the dry season (Fig. 6d). For arid regions, the limiting effect of water is much greater than the limiting effect of energy (Roderick et al. 2014). Compared to the wet season, the contribution of precipitation in the dry season declined slightly, but it was still dominant. Although the role of $E_{0}$ is small, the spatial effects of $E_{0}$ varied by region and need further exploration.

Dry season spatial patterns of the Budyko-Penman budget components (Fig. 7) indicate that $P$ was enhanced over almost all CA, with the largest trend being over Tien Shan (Fig. 7c). As shown in Eq. (10), $\langle\partial(P-E) / \partial P\rangle$ was determined by the climatology of $P, E, n$, and $E_{0}$ [Eq. (10a)]. Apart from northwestern Xinjiang and northeastern CA, the contribution of $P$ to the $P-E$ change was negative (Fig. 7a). An insignificant decrease in $T_{a}$ was recorded in Kazakhstan and the Tarim Basin (Fig. 7f). The term $\left\langle\partial(P-E) / \partial T_{a}\right\rangle$ consists of $E, P, E_{0}$, 

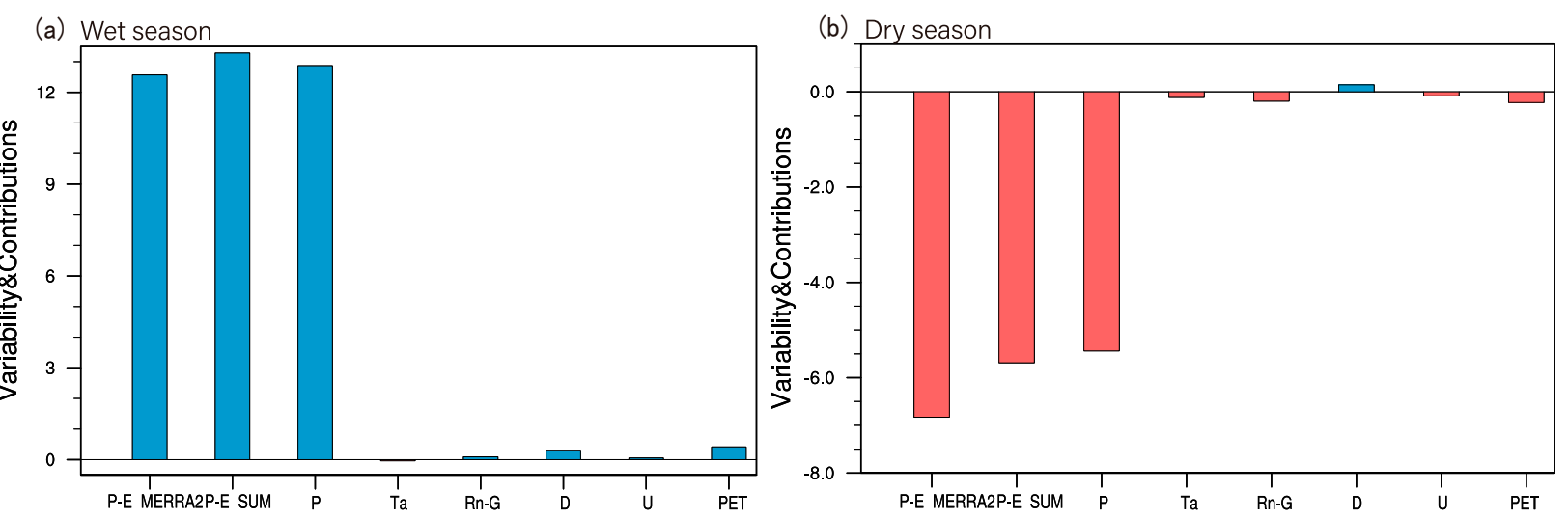

(c) Wet season
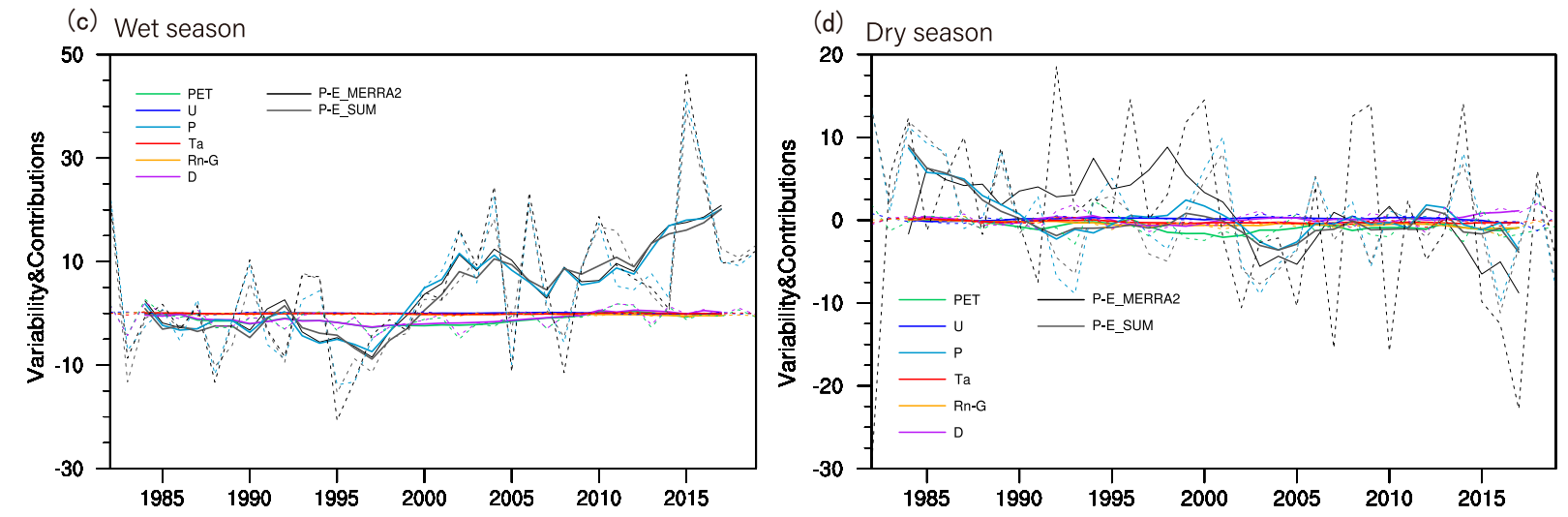

FIG. 6. (a) The regional area-averaged contributions of Budyko-Penman budget components for the difference of $P-E\left[\mathrm{~mm}(6 \mathrm{months})^{-1}\right.$ ] between the 2001-19 and 1982-2000 periods (the former minus the latter) in wet season over CA. The term "P-E_MERRA2" is the change in $P-E$ calculated directly by precipitation and evapotranspiration of MERRA2; "P-E_SUM" is the sum of the contributions of the factors obtained by the decomposition. (b) As in (a), but for the dry season. (c) Changes in 6-month total $P-E$ relative to the 1982-88 baseline and contributions of individual climate factors [mm $(6 \text { months })^{-1}$ ] affecting it in the wet season over CA. The color lines of $P, D, U, R_{n}-G, T_{a}$, and $E_{0}$ represent their contribution to $P-E$ changes rather than their own changes. (d) As in (c), but for the dry season. The climate factors include precipitation $(P)$, pressure deficit $(D)$, wind speed $(U)$, the net radiation $\left(R_{n}-G\right)$, near-surface air temperature $\left(T_{a}\right)$, and potential evapotranspiration $\left(E_{0}\right)$.

$R_{n}-G, T_{a}$, and $U$ [Eq. (10c)], which was less than 0 in the south of Kazakhstan and the mountains (Fig. 7e). Due to the canceling effect with negative and positive trends of $T_{a}$ and $\left\langle\partial(P-E) / \partial T_{a}\right\rangle$ distribution in Uzbekistan and other regions, the $T_{a}$ term only had a minor contribution to $P-E$ changes (Figs. $7 \mathrm{~d}$ and $6 \mathrm{c}$ ). In addition, the changes in wind speed were negative over Xinjiang (Fig. 7i). The term $\langle\partial(P-E) / \partial U\rangle$ was determined by $P, E, n, E_{0}, \mathrm{RH}, U, R_{n}-G$, and $T_{a}$ [Eq. (10d)], and it was uniformly negative across CA (Fig. 7h). As a strengthened surface wind was conducive to evaporation, its contribution to $P-E$ was negative, resulting in opposite distributions (Figs. $7 \mathrm{~g}, \mathrm{i}$ ). Notably, $D$ had a prominent decline and increase along central CA and the east-west boundary (Fig. 71), with changes in $D$ being associated with changes in $T_{a}$ (Fig. 7f). The term $\langle\partial(P-E) / \partial D\rangle$ is a function of $P, E, n$, $E_{0}, T_{a}, U$ and $R_{n}-G$ [Eq. (10e)], and decreasing $D$ was the result of enhanced evaporation, which can affect evaporation demand, thereby promoting an increase in $P-E$ (Fig. 7j). The results indicated significant positive trends in $R_{n}-G$ over the majority of regions in central and northern CA (Fig. 7o). As $\left\langle\partial(P-E) / \partial\left(R_{n}-G\right)\right\rangle$ is a function of $P, E, n, E_{0}$, and $T_{a}$ [Eq. (10b)], it was negative across the entire area (Fig. 7n). An increase (decrease) in $R_{n}-G$ resulted in an increase (decrease) in $E$, resulting in a decrease (increase) in $P-E$; the contribution of $R_{n}-G$ was contrary to the change in $R_{n}-G$ (Figs. 7m,o).

During the wet season, the spatial patterns of BudykoPenman budget components (Fig. 8) indicated that precipitation had a significant increasing trend in CA, except for Tajikistan (Fig. 8c). The term $\langle\partial(P-E) / \partial P\rangle$ is of opposite sign between the five countries in CA and Xinjiang (Fig. 8b), resulting in a similar contribution of $P$ to the distribution of $\langle\partial(P-E) / \partial P\rangle$ (Figs. 8a,b). As observed in the results when $T_{a}$ was weakened (Fig. 8f), a weakening of $D$ was recorded in eastern Kazakhstan and the Tarim Basin (Fig. 81). Compared with the dry season, wind speed during the wet season declined in most areas (Figs. 7i and 8i), with $\langle\partial(P-E) / \partial U\rangle$, $\langle\partial(P-E) / \partial D\rangle$, and $\left\langle\partial(P-E) / \partial\left(R_{n}-G\right)\right\rangle$ having negative values across the entire area (Figs. $8 \mathrm{~h}, \mathrm{k}, \mathrm{n}$ ). A decrease in $U$ and $D$ was accompanied by a decrease in $E, U$, and $D$, and 

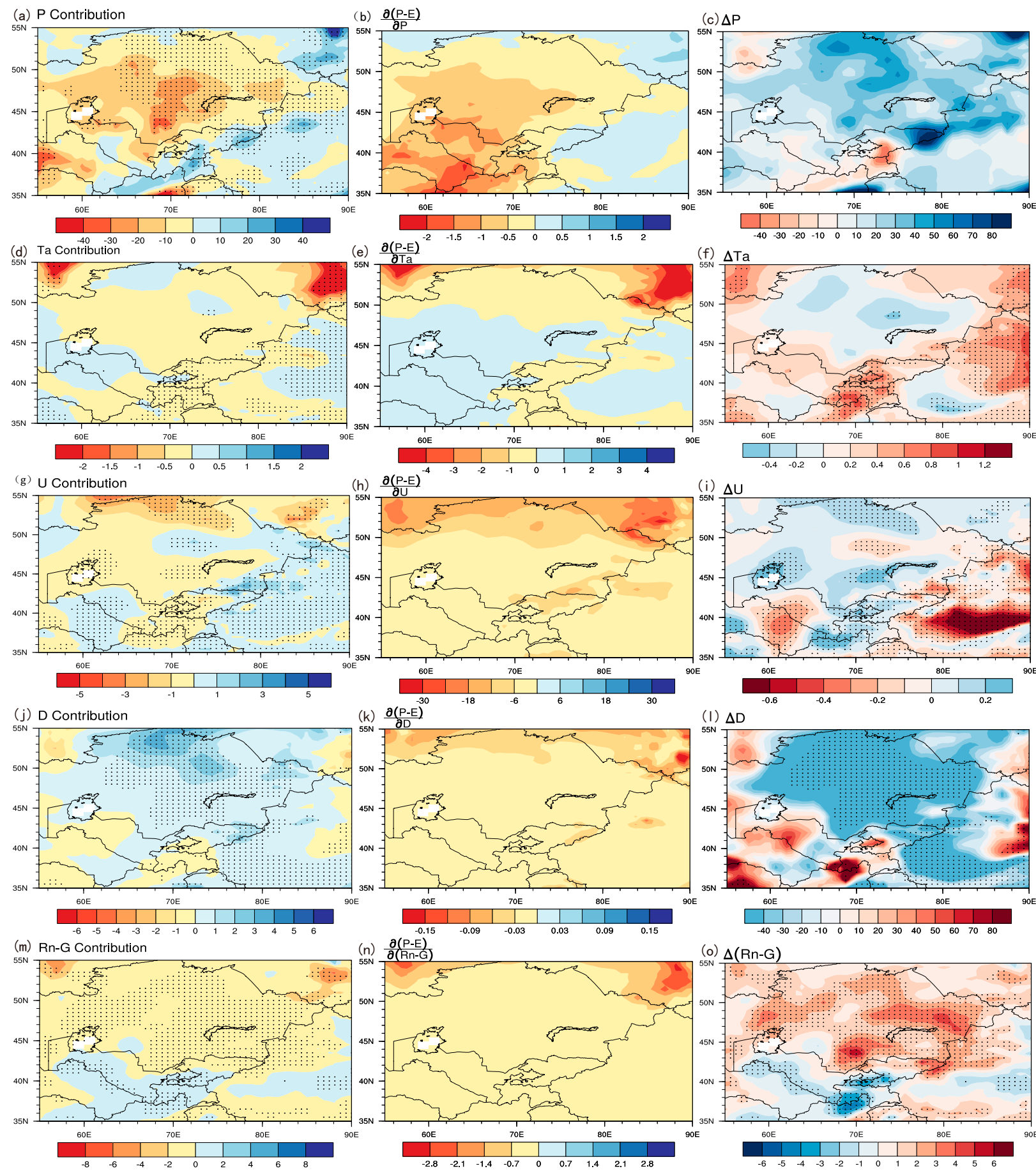

FIG. 7. The spatial patterns of Budyko-Penman budget components for $P-E$ changes between 2001-19 and $1982-2000$ for the dry season. The results from (a)-(c) precipitation $\left[\mathrm{mm}(6 \text { months })^{-1}\right]$, (d)-(f) near-surface temperature $(\mathrm{K})$, (g)-(i) wind speed (m s $\left.{ }^{-1}\right)$, (j)-(l) vapor pressure deficit $(\mathrm{Pa})$, and $(\mathrm{m})-(\mathrm{o})$ net radiation $\left(\mathrm{W} \mathrm{m}^{-2}\right)$. The components of (left) contribution to $P-E$ change $\left[\mathrm{mm}(6 \mathrm{months})^{-1}\right]$, (center) sensibility, and (right) difference in themselves between 2001-10 and 1982-2000.

therefore had positive contributions to the change in $P-E$ in many areas (Figs. 8g,i,j,l). One difference, however, was that the positive contribution of wind speed was mainly evident in Xinjiang and Kazakhstan, while that of $D$ was mainly evident in the north-central part of CA. The changes in $R_{n}-G$ varied across the region (Fig. 80) and were conducive to higher $P-E$ in central CA; other areas had opposite trends (Fig. 8m). 
(a) P Contribution

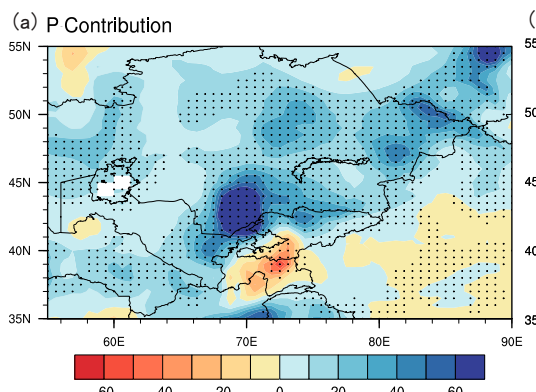

(d) Ta Contribution

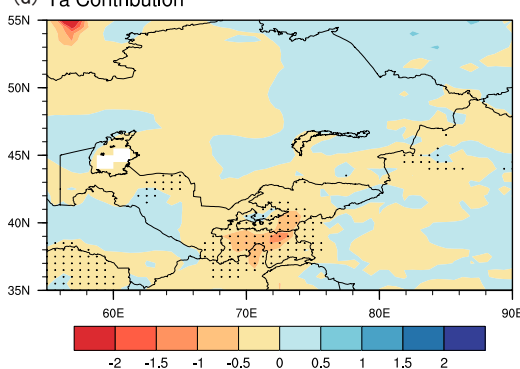

(g) U Contribution
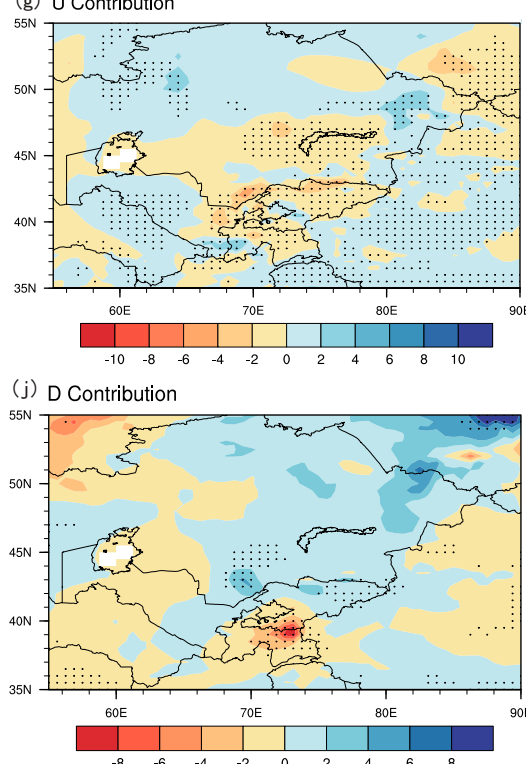

(m) Rn-G Contribution

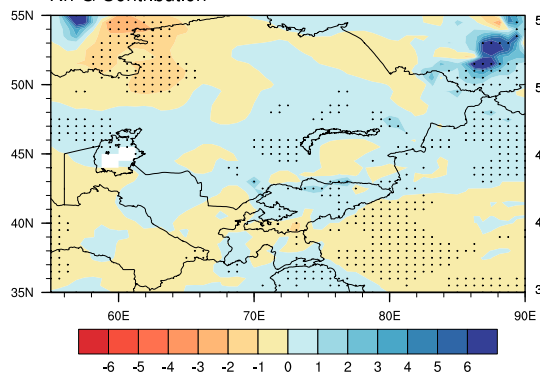

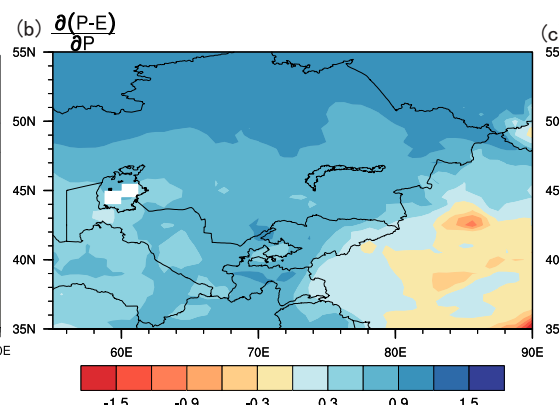
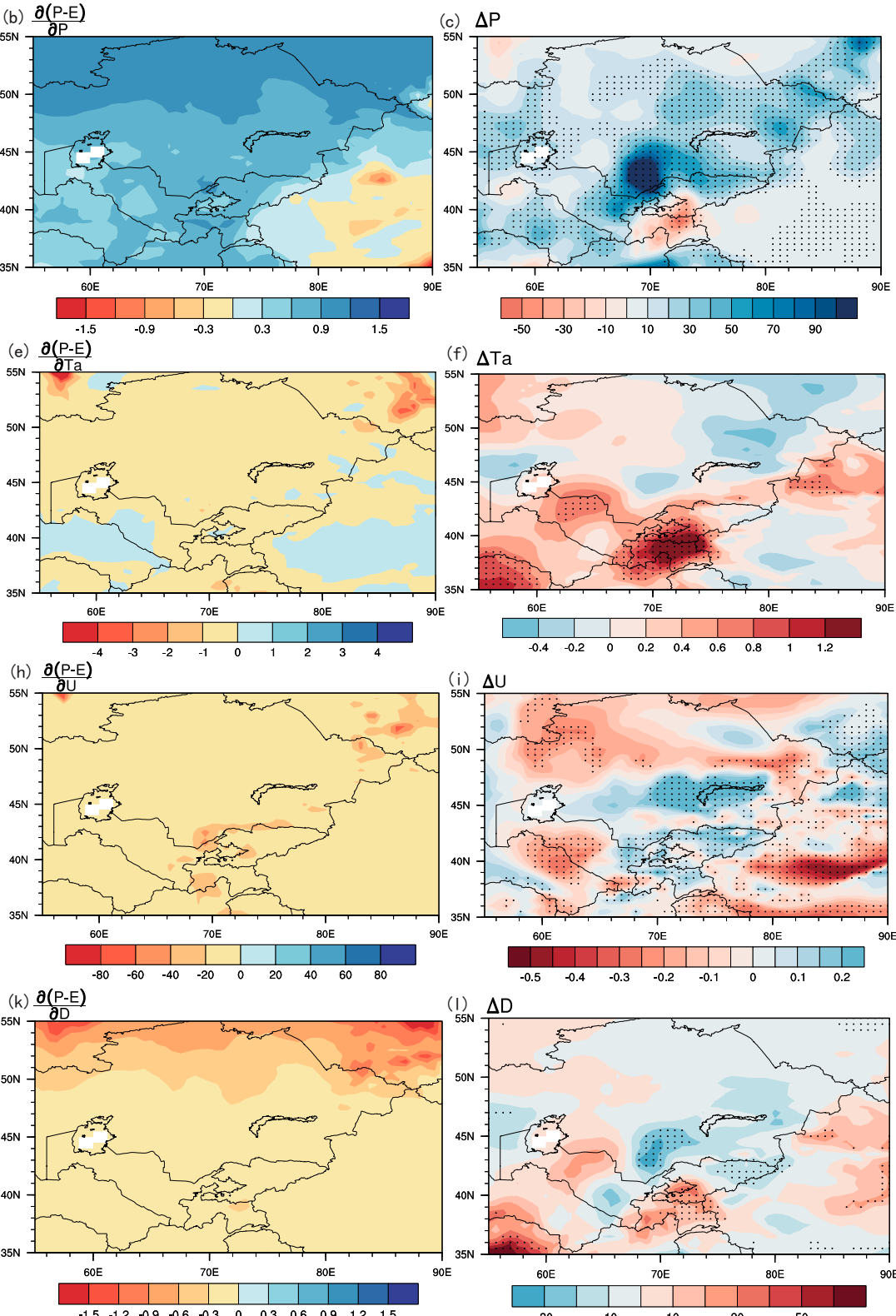

(n) $\partial(P-E)$

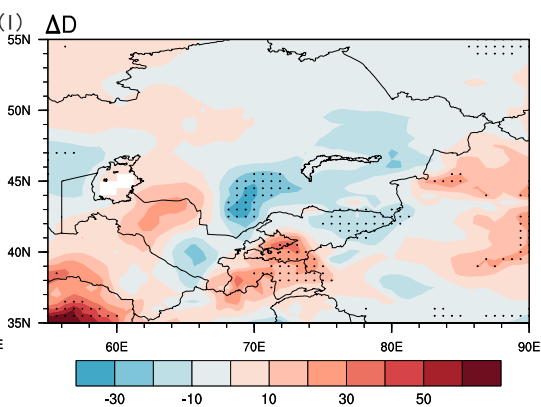

(o) $\Delta(\mathrm{Rn}-\mathrm{G})$
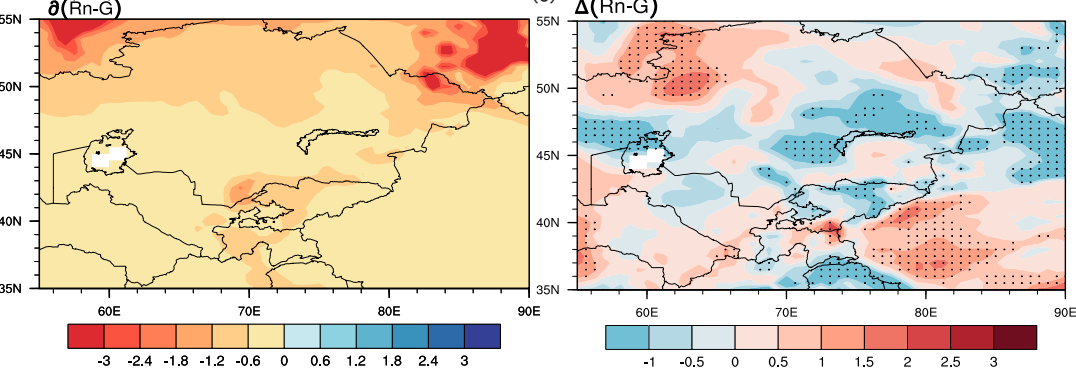

FIG. 8. As in Fig. 7, but for the wet season. 
(a) Wet season differcence of $200 \mathrm{hPa}$ GPH

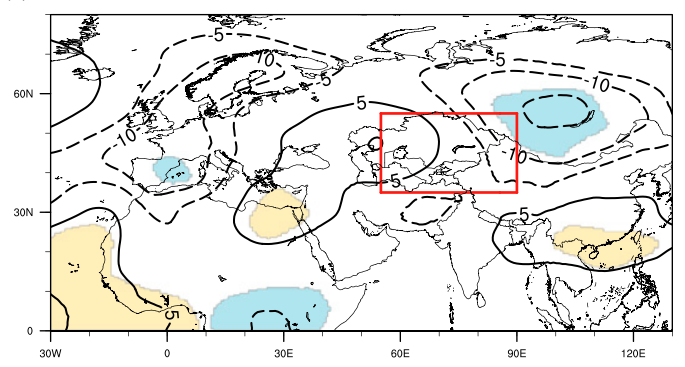

(c) Wet season
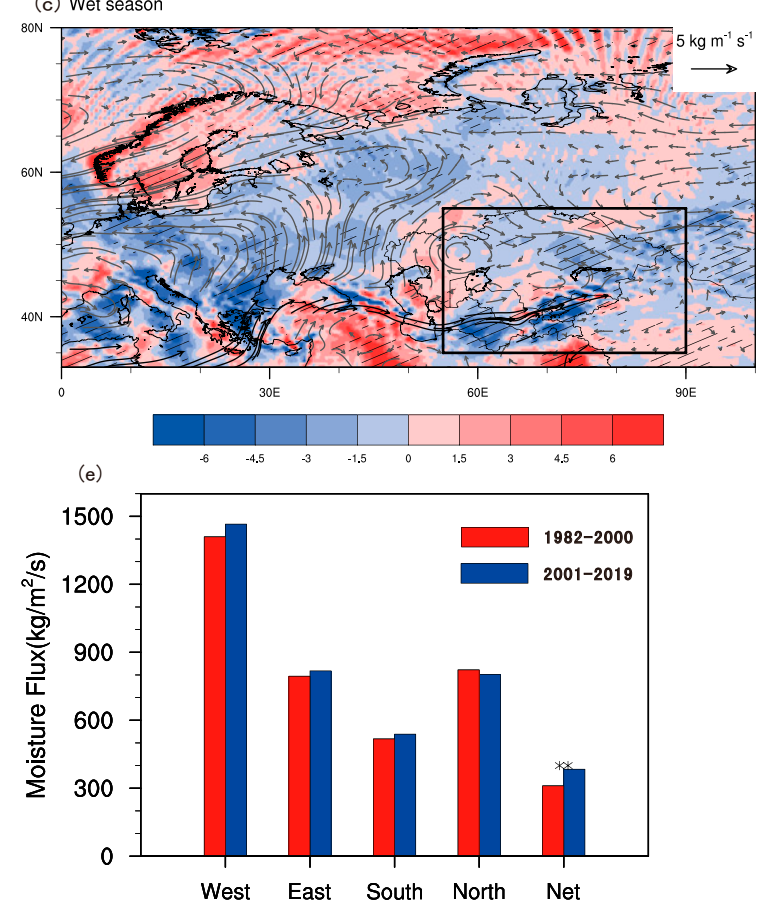

(b) Dry season differcence of $200 \mathrm{hPa}$ GPH

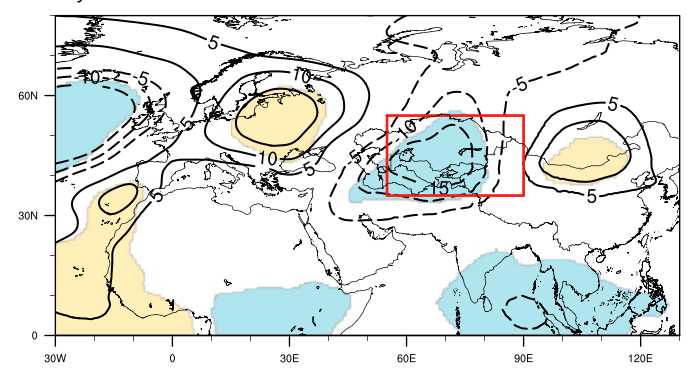

(d) Dry season
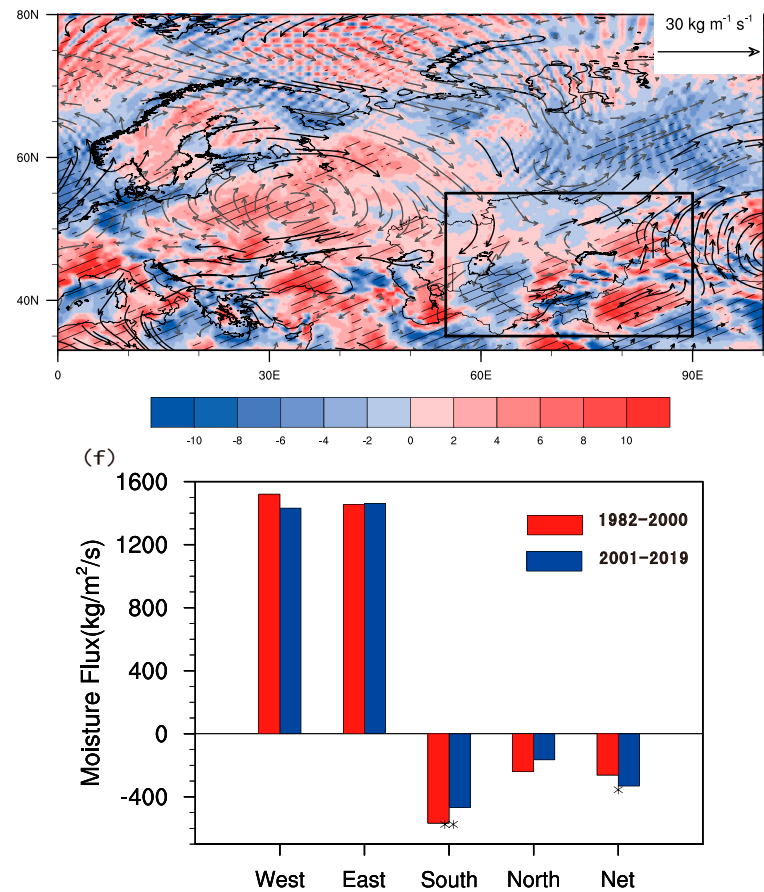

FIG. 9. The differences in eddy 200-hPa geopotential height (gpm) between 1982-2000 and 2001-19 in (a) the wet season and (b) the dry season. The black line represents the contour, and color shadings indicates that the differences are significant at the 0.1 level. The corresponding composite differences of integrated water vapor in (c) the wet season and (d) the dry season. The color shadings indicate the moisture flux divergence $\left(\mathrm{kg} \mathrm{m}^{-2} \mathrm{~s}^{-1}\right)$, and the black shaded slash indicates that the differences in moisture flux divergence are significant at the 0.1 level. The gray vectors indicate the integrated water vapor flux $\left(\mathrm{kg} \mathrm{m}^{-1} \mathrm{~s}^{-1}\right)$, and black vectors represent the significant difference at the 0.1 level. (e) Moisture flux $\left(\mathrm{kg} \mathrm{m}^{-1} \mathrm{~s}^{-1}\right)$ on different boundaries in two periods for the wet season. (f) As in (e), but for the dry season. We define westerly and southerly winds as positive. The northerlies and easterlies are recorded as negative values. One asterisk $(*)$ indicates that the difference is significant at the 0.1 level, and two asterisks $(* *)$ indicate that the difference is significant at the 0.05 level.

Our results provide credible explanations for the drying trend in the dry season and the wetting trend in the wet season in CA related to precipitation. It should be noted that $P$ in the wet season has a positive contribution to the increasing trend of $P-E$; the positive contribution of $P$ in the dry season for a decreasing $P-E$ trend was due to local $E$ exceeding $P$. Stronger changes in net radiation, surface air temperature, and vapor pressure deficit in the dry season also caused an increase in their contribution to $P-E$ compared with the wet season. As $P$ and $E$ were also key factors in the atmospheric moisture balance, we also performed attribution analysis.

\section{Atmospheric water budget analysis}

To further clarify the driving mechanisms of wetting/drying through the atmospheric water vapor mass equation, we examined the relationships among $P-E$ changes, moisture sources, and atmospheric circulations based on the $P-E$ decadal variations. The differences in eddy $200-\mathrm{hPa}$ geopotential height, integrated water vapor, and moisture flux divergence are shown in Fig. 9. By combining Figs. 9a-d, it can be seen that $200-\mathrm{hPa}$ atmospheric circulations generally guide water vapor transmission. For the wet season, water vapor transported from the Mediterranean Sea significantly 
increased south of the western boundary of CA (Fig. 9c). The increase in net water vapor inflow was $72.85 \mathrm{~kg} \mathrm{~m}^{-1} \mathrm{~s}^{-1}(p<$ $0.05)$, adhering to a $6.43 \times 10^{-6} \mathrm{~kg} \mathrm{~m}^{-2} \mathrm{~s}^{-1}(p<0.05)$ decrease in water vapor flux divergence. For the dry season, a cyclonic anomaly in middle CA was accompanied by two anticyclonic anomalies on both sides (Fig. 9b), and anomalous water vapor was transported from the Arabian Sea to CA (figure not shown), which was influenced by the negative phase of EA-WR that caused the anomalous cyclone and deepens the trough over CA (Ma et al. 2020). Water vapor outputs significantly decreased as the southern boundary was dominated by southerlies (Fig. 9d). The increase in moisture exports in CA during the dry season was $74.41 \mathrm{~kg} \mathrm{~m}^{-1} \mathrm{~s}^{-1}$ $(p<0.1)$, and the changing magnitude of water vapor flux divergence was $2.72 \times 10^{-6} \mathrm{~kg} \mathrm{~m}^{-2} \mathrm{~s}^{-1}$. In summary, the enhanced net inflow of moisture resulted in a wetter wet season, and for the dry season the opposite is true.

Despite the drying trend during the dry season, precipitation increased (Fig. 4b). To further analyze the reasons for this occurrence, we calculated the recycling ratio using the DRM. Differences between the precipitation recycling ratio ( $\rho$ ) for 2001-19 and 1982-2000 in the wet season and dry season within CA were calculated using Eq. (14). From 1982 to 2000 , the recycling ratio was $23.24 \%$ in the wet season and $52.77 \%$ in the dry season for the entire CA region, whereas from 2001 to 2019 , the recycling ratio in the two seasons was $24.84 \%$ and $57.46 \%$, respectively.

During the wet season, the increase in $\rho$ almost synchronized the increase in longitude from west to the east in CA, with a significant increase near the Tarim Basin (Fig. 10a). Precipitation induced by the internal cycle and by the external cycle were both enhanced over almost the entire CA region, while the rise in the former was much less than that in the latter, which indicated that the increase in wet season precipitation was mainly dominated by increased precipitation induced by the external cycle (Figs. 10c,e). In other words, the wetter wet season was caused by the increasing contribution of both local and advected moisture to precipitation and the amount of water vapor transported from outside the region (Figs. 9e and 10c). The consequences of an increase in $\rho$ were a stronger growth rate of recycled precipitation $(32.16 \%)$ than that of externally cycled precipitation $(17.86 \%)$. However, the advective moisture was mainly responsible for the wet season precipitation ( $\rho$ was low compared with the dry season), and the increase in externally cycled precipitation [11.93 mm (6 months $\left.)^{-1} ; p<0.05\right]$ is much greater than that in recycled precipitation $\left[5.96 \mathrm{~mm}(6 \text { months })^{-1} ; p<\right.$ 0.01]. For the dry season, regions of decreasing $\rho$ occurred in the Kunlun and Pamir Mountains, while regions of significantly increasing $\rho$ were located in the majority of areas in CA (Fig. 10b). The weak increase in precipitation induced by the external cycle was $3.18 \mathrm{~mm}$ (6 months) ${ }^{-1}$ (Fig. 10f), possibly related to an increase in precipitation efficiency (Sui et al. 2005, 2007). An increase in precipitation was mainly caused by a remarkable increase in local evapotranspiration consistent with the enhancement of recycled precipitation $[16.10 \mathrm{~mm}$ (6 months) $)^{-1} ; p<0.1$ ] (Fig. 10d); this finding does not contradict the results indicating that the dry season became drier.
To more clearly explain the contribution of moisture sources associated with precipitation to the target area, the moisture-source tracking method was used. Climatological maps (Figs. 11a,b) show an indicator of spatial moisture contributions, and the moisture in the target area was mostly from CA, northern Eurasia, midwestern Eurasia, western Eurasia, the Atlantic Ocean, the Arctic Ocean, the Indian subcontinent and the Indian Ocean, North Africa, and West Asia. During the wet season, midwestern Eurasia had the highest uptake of water vapor $(26.23 \%)$, and moisture source regions of moisture uptake ranking second $(23.88 \%)$ and third (18.44\%) were CA and the northern Atlantic Ocean, respectively (Figs. 11a,e); more water vapor originated from westerly airflows compared with the dry season (Figs. 11a,b). On a decadal difference of the 19-yr mean, moisture sources in midwestern Eurasia, North Africa, and West Asia had an increase of $1.55 \%(p<0.1), 0.84 \%$, and $0.34 \%$, respectively, with a $2.04 \%(p<0.05)$ decrease in moisture from the North Atlantic Ocean (NAL) (Fig. 11c). For the dry season, the moisture source region where the contribution level ranked first was CA (36.20\%), followed by midwestern (19.46\%) and northern Eurasia (18.52\%) (Fig. 11e). A comparison between 2001-19 and 1982-2000 showed that local and westerly moisture sources played opposite roles, with the former rising and the latter falling. Local and Indian evaporative moisture had greater moisture contributions [increase of by $2.34 \%(p<$ $0.05)$ and $0.58 \%(p<0.05)$, respectively], while that in midwestern Eurasia decreased by $2.34 \%(p<0.05)$ (Figs. 11d,f). It should be noted that the corresponding moisture trajectories followed a $2 \mathrm{D}$ wind field since the $\mathrm{DRM}$ is a $2 \mathrm{D}$ model. The DRM does not consider the vertical shear of the horizontal wind. If the wind directions at high and low altitudes are opposite, the water vapor transport generated is different from that of the vertically averaged $2 \mathrm{D}$ wind velocity, and the direction of moisture transport of local origin and that of remote origin can be different (Van der Ent and Savenije 2013; Martinez and Dominguez 2014). In addition, due to the limited resolution of reanalysis data, steep regional topography is not fully considered, which may give rise to uncertainty in the estimation of regional atmospheric moisture transport. Indeed, not all moisture sources tracked by the DRM are convincing. For instance, the contribution of the deserts in Turkmenistan in the wet season is abnormally large (Fig. 11a), which is not convincing.

\section{Conclusions and discussion}

To quantitatively and comprehensively explore the reasons for changes in hydrology over CA in recent decades, we discussed this issue from two perspectives: the atmospheric moisture budget and the surface water budget. The combined roles of $P$ and $E$ are intimately linked to the two budgets, making it a good indicator to estimate climate dryness/wetness. We used the MERRA2 dataset to analyze the meridional mean climatology and trend of $P-E$, and the season in which $P-E$ was less than 0 (April-September) was defined as the dry season; October-March was defined as the wet 
(a) Wet season change of recyling ratio

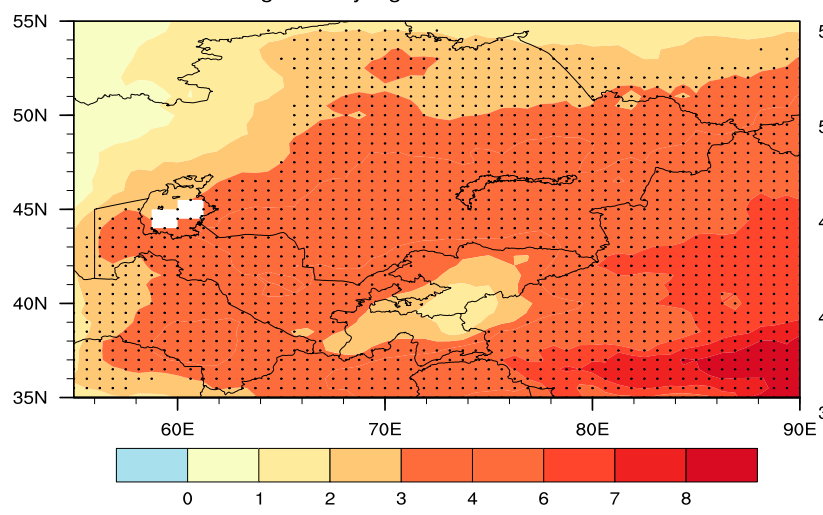

(c) Wet season change of $P$ induced by internal cycle

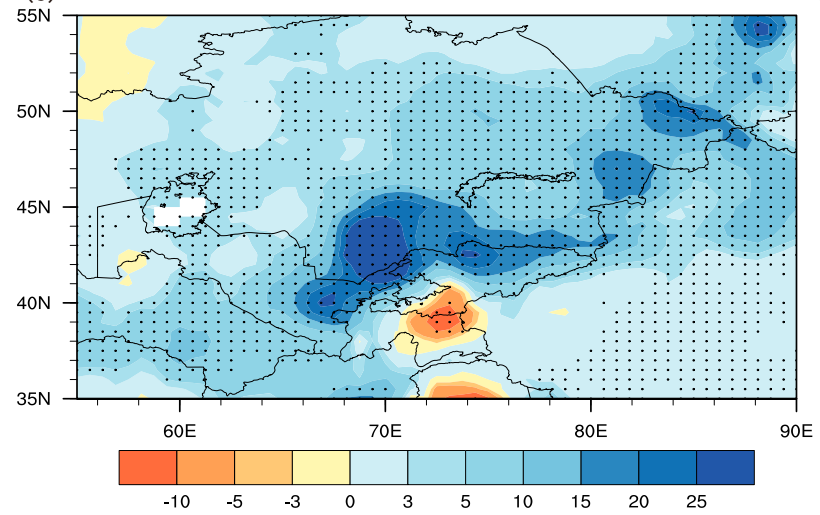

(e) Wet season change of $P$ induced by external cycle

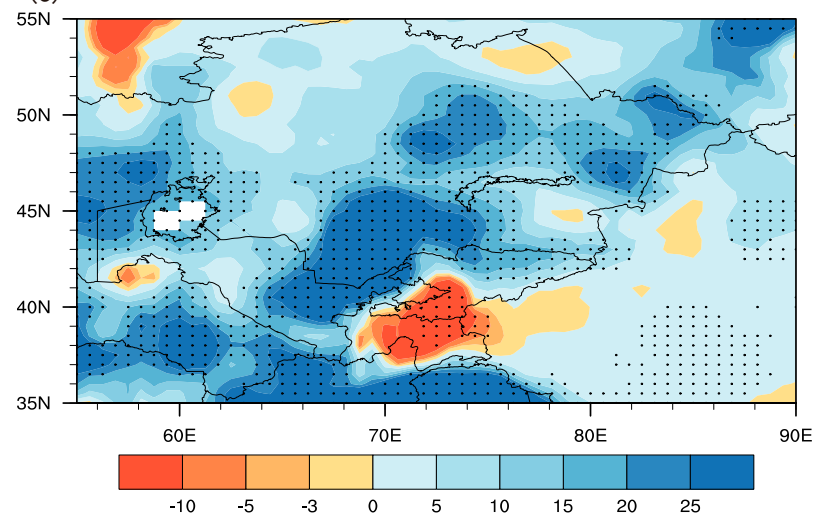

(b) Dry season change of recycling ratio

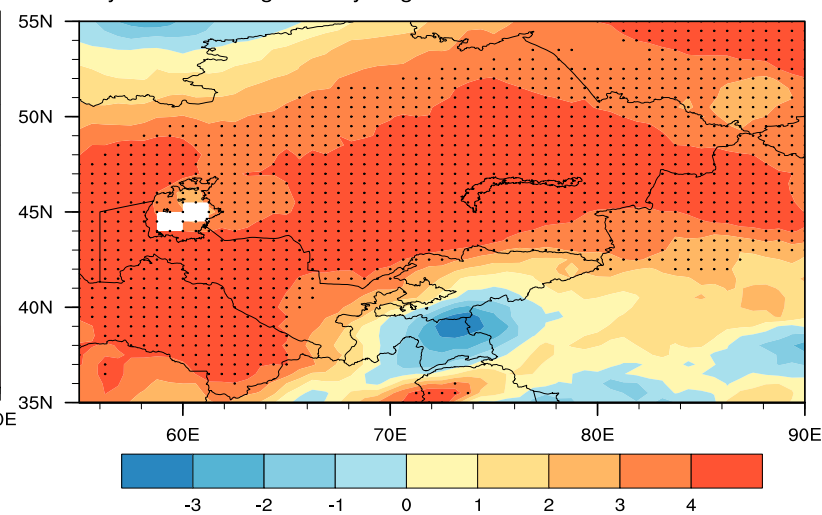

(d) Dry season change of $\mathrm{P}^{-1}$ induced by internal cycle $^{-3}{ }^{-2}$

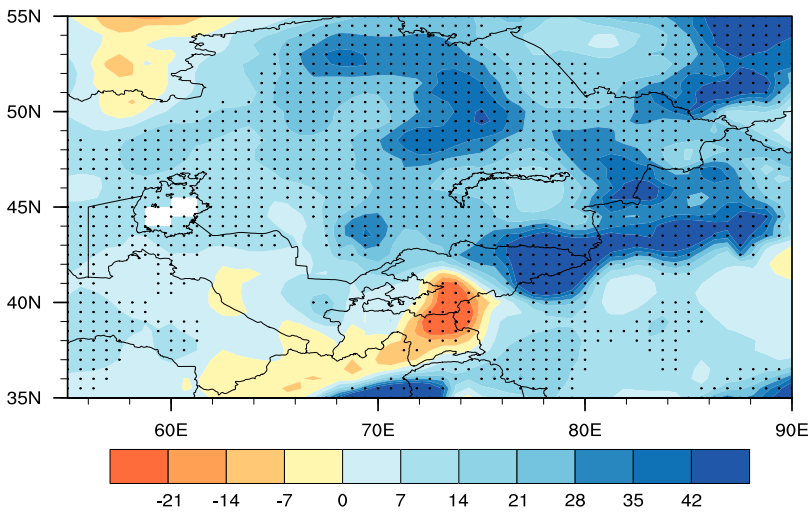

(f) Dry season change of $P$ induced by external cycle

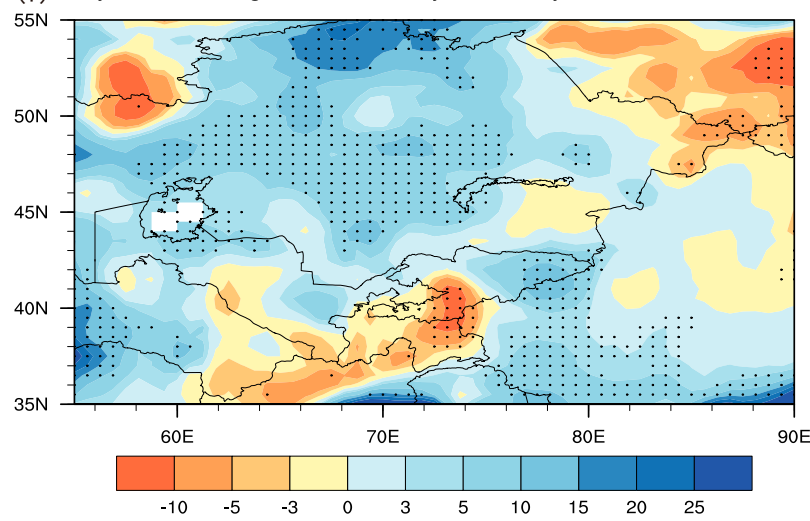

FIG. 10. Spatial patterns of differences between 1982-2000 and 2001-19 for (a),(b) recycling ratio (\%), (c),(d) precipitation induced by internal cycle $\left[\mathrm{mm}(6 \mathrm{months})^{-1}\right]$, and (e),(f) precipitation induced by external cycle [mm (6 months) $\left.)^{-1}\right]$ in the (left) wet season and (right) dry season. The precipitation induced by internal cycle is precipitation from local evaporation. The precipitation induced by external cycle is precipitation from advected moisture. The dotted areas indicate differences that are significant at the 0.1 level.

season. The phenomenon of the dry season becoming drier and wet season becoming wetter was identified in CA from 1982 to 2019. By calculating cumulative anomalies, a noticeable turning point in $P-E$ change was found approximately 2000/01, indicating the multidecadal variations in $P-E$. Therefore, we divided the study period into two periods: 1982-2000 and 2001-19.

From the perspective of the surface water budget, we decomposed the Budyko-Penman equation to quantify the contributions of individual climatic factors to $P-E$ changes between 2001-19 and 1982-2000. Precipitation was found to be the dominant factor affecting $P-E$ wet and dry seasons. The impacts of individual climatic factors were therefore $P(95.43 \%), R_{n}-G(3.51 \%), D(-2.64 \%), T_{a}(2.11 \%)$, and $U(1.41 \%)$. In the wet season, the contributions of individual climatic factors were precipitation $(96.84 \%), D(2.26 \%)$, $R_{n}-G(0.70 \%), U(0.47 \%)$, and $T_{a}(-0.31 \%)$. The $R_{n}-G$, $D$, and $T_{a}$ terms were more responsible for changes in $P-E$ 
(a) $1982-2000$ Wet season

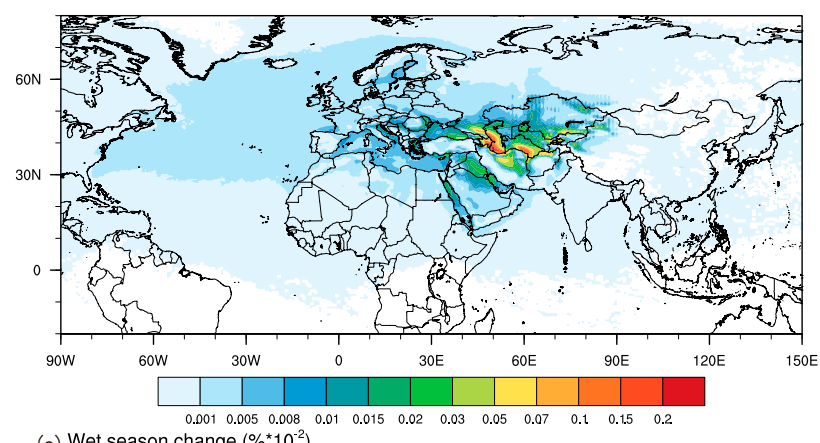

(c) Wet season change $\left(\% \%^{*} 10^{-2}\right)$
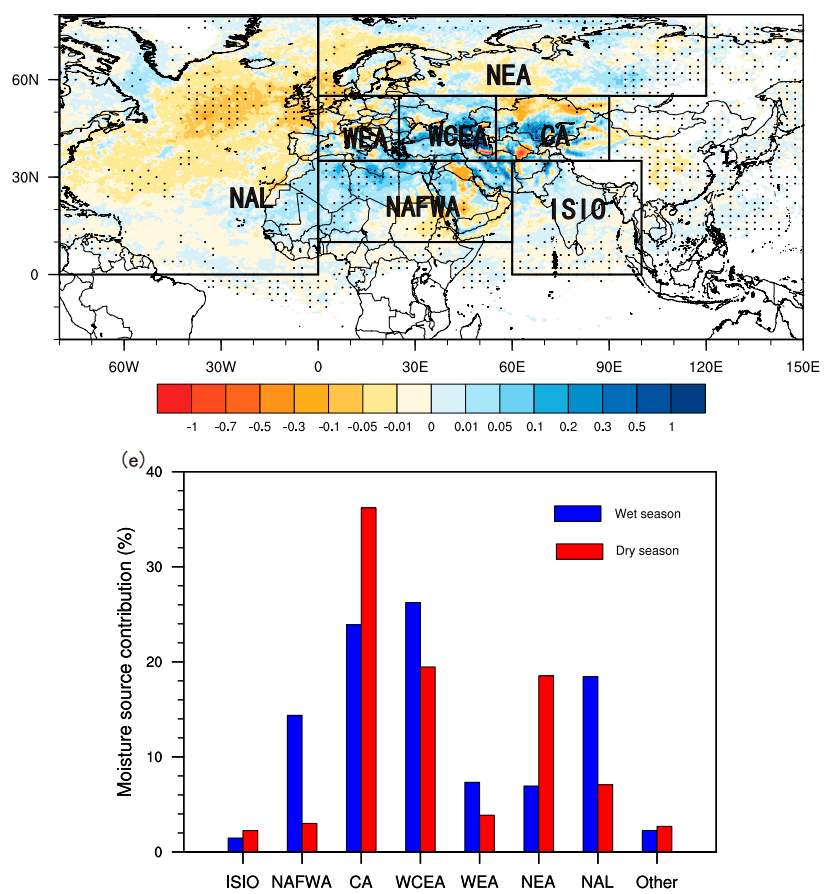

(b) 1982-2000 Dry season

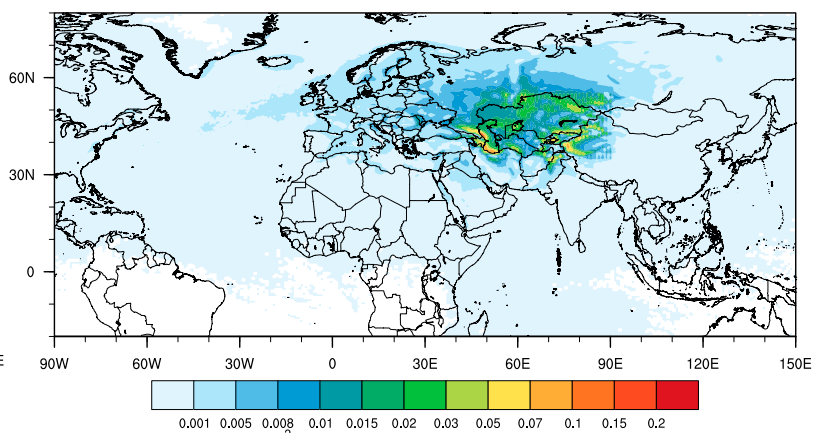

(d) Dry season change $\left(\% \%^{*} 10^{-2}\right)$
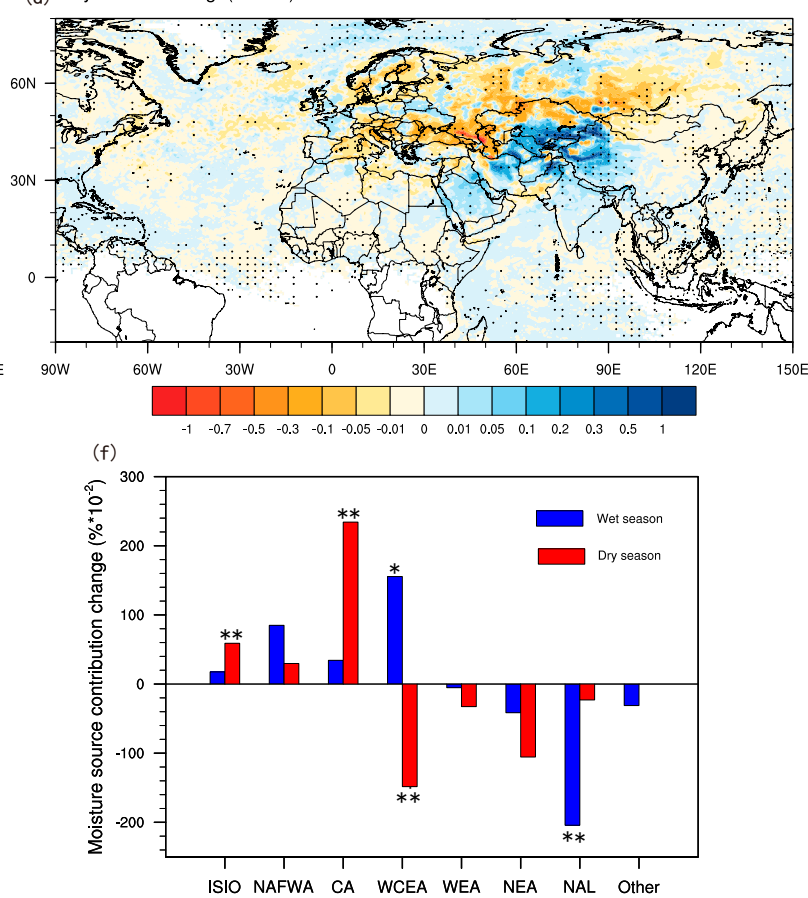

FIG. 11. The spatial patterns and the spatiotemporal average of contributions from the moisture-source regions for CA's precipitation. (a) 1982-2000 mean for the wet season, (b) 1982-2000 mean for the dry season, (c) difference of 2001-19 mean and 1982-2000 mean for wet season, (d) difference of 2001-19 mean and 1982-2000 mean for dry season, (e) the spatiotemporal average of 1982-2000 in two seasons, and (f) spatiotemporal difference of 2001-19 mean and 1982-2000 mean in two seasons (the unit is \% for mean and \% $\times 10^{-2}$ for difference). The black boxes in (c) represent the defined geographic regions: the North Atlantic Ocean (NAL: $\left.80 \mathrm{~W}^{\circ}-0^{\circ}, 0^{\circ}-80^{\circ} \mathrm{N}\right)$, northern Eurasia (NEA: $0^{\circ}-120^{\circ} \mathrm{E}, 55^{\circ}-80^{\circ} \mathrm{N}$ ), western Eurasia (WEA: $0^{\circ}-25^{\circ} \mathrm{E}, 35^{\circ}-55^{\circ} \mathrm{N}$ ), midwestern Eurasia $\left(\mathrm{WCEA}: 25^{\circ}-55^{\circ} \mathrm{E}, 35^{\circ}-55^{\circ} \mathrm{N}\right.$ ), central Asia $\left(\mathrm{CA}: 35^{\circ}-55^{\circ} \mathrm{E}, 50^{\circ}-95^{\circ} \mathrm{N}\right)$, North Africa and West Asia (NAFWA: $0^{\circ}-60^{\circ} \mathrm{E}, 10^{\circ}-35^{\circ} \mathrm{N}$ ), and the Indian subcontinent and the Indian Ocean (ISIO: $60^{\circ}-100^{\circ} \mathrm{E}, 0^{\circ}-35^{\circ} \mathrm{N}$ ). The dotted areas indicate differences that are significant at the 0.1 level for (c) and (d). One asterisk (*) indicates that the difference is significant at the 0.1 level, and two asterisks (**) indicate that the difference is significant at the 0.05 level.

based on comparative analyses in the dry season compared with those in the wet season.

From the perspective of the atmospheric moisture budget, for the wet season, upper-tropospheric circulation anomalies in the mid-high latitudes with enhanced net inflow into CA were identified as the major cause of the enhanced moisture transportation. Midwestern Eurasia, local regions, and the North Atlantic were the most important water vapor source regions for CA precipitation. The enhancement of recycled precipitation and the externally cycled precipitation both contributed to the increased total precipitation in the wet season. Compared with 1982-2000, the externally cycled precipitation increased by $11.93 \mathrm{~mm}$ (6 months) ${ }^{-1}$ and moisture origins from midwestern Eurasia and CA had significant contributions to the increase in water vapor flux between 2001 and 2019. For the dry season, there was a " +-+ " anomalous upper-tropospheric circulation pattern in Eurasia, accompanied by an increase in the divergence of water vapor flux. Important moisture source areas for precipitation were local regions, midwestern Eurasia and North Eurasia. The decrease 
(a) Difference of wet season ERSST

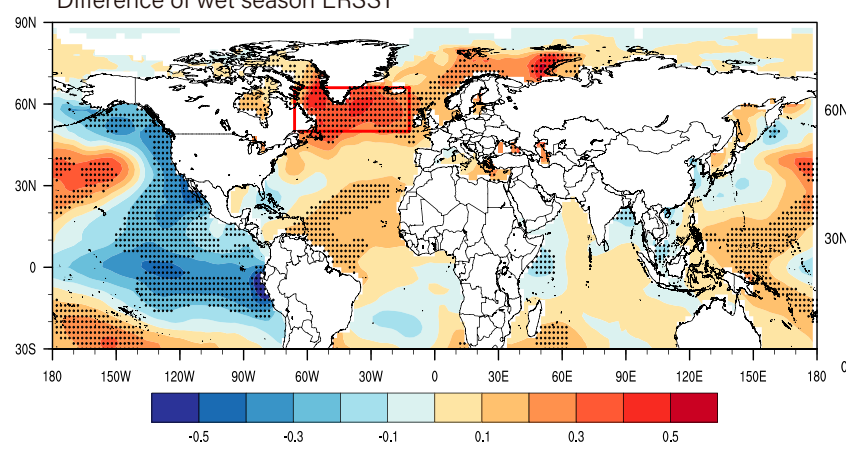

(c) Difference of dry season ERSST

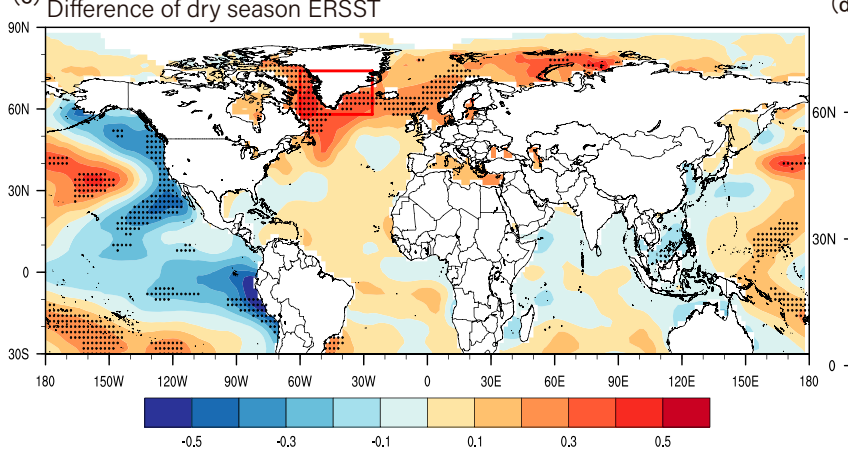

(b)

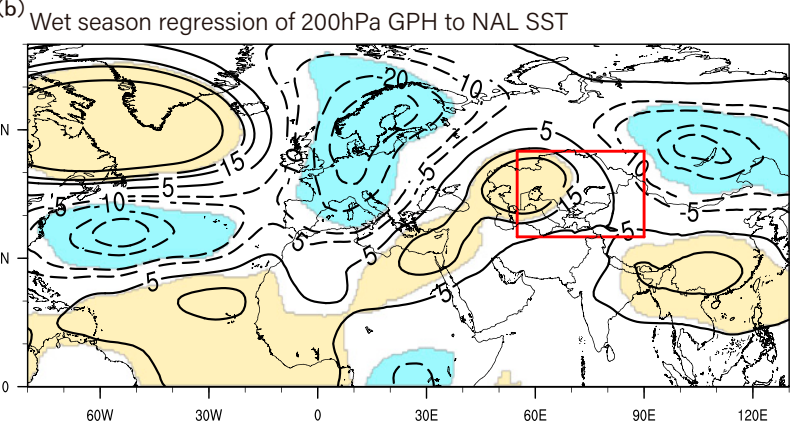

(d) Dry season regression of $200 \mathrm{hPa}$ GPH to NAL SST

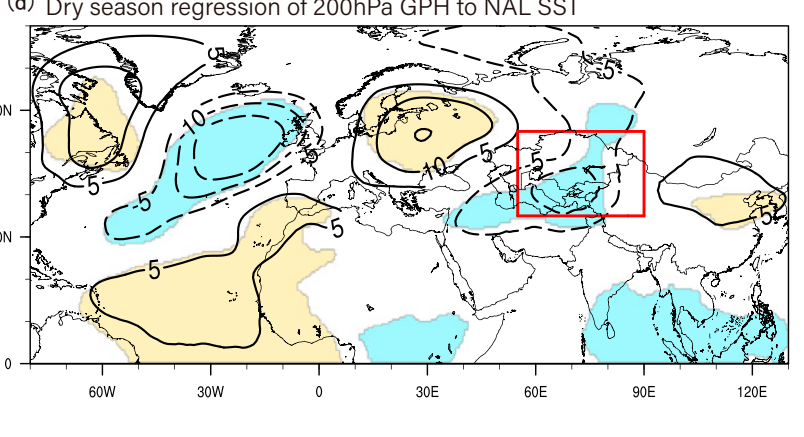

FIG. 12. Differences in detrended ERSST $\left({ }^{\circ} \mathrm{C}\right)$ in the (a) dry season and (c) wet season between 2001-19 and 1982-2000. The trend of global mean sea temperature is removed from the original series of ERSST to explore the interdecadal variability in sea temperature. The dotted areas indicate differences that are significant at the 0.1 level. (b) The regression coefficient between eddy 200-hPa geopotential height and the averaged ERSST over the red box in (a) on interdecadal time scales during 1982-2019 in the wet season. (d) As in (b), but for the dry season. The color shadings indicate that the regression coefficients are significant at the 0.1 level. Both ERSST and geopotential height in (b) and (d) are low-pass filtered for 9 years to extract their interdecadal variations.

in $P-E$ was mainly associated with a $4.69 \%$ increase in the recycling ratio, with a decrease in midwestern Eurasian moisture contributions and an increase in local and Indian moisture contributions. The enhancement of evapotranspiration resulted in an increase in precipitation during the dry season. These results demonstrate the important influence of local land surface processes on regional precipitation.

Previous studies have demonstrated that some positive patterns have an influence on precipitation in CA on different time scales, such as El Niño-Southern Oscillation (ENSO) (Hoell et al. 2015, 2017; Barlow et al. 2002, 2016; Gerlitz et al. 2018), the Atlantic multidecadal oscillation (AMO) (Li et al. 2008), and the North Atlantic Oscillation (NAO) (Syed et al. 2010); all of the above have a close relationship to the variability in SST, which mostly modulates the atmospheric circulation and water vapor transport path to influence CA precipitation. In this article, the interdecadal transition in $P-E$ in approximately 2000 was identified in both seasons (Figs. 5a,b). To further explore the possible linkage of how the SST variability affects changes in $P-E$ in CA, we first analyzed the changes in global SST based on the decadal transition. To highlight the effect of decadal variability, the SST was preprocessed by removing the global average SST trend over 1982-2019. As shown in Figs. 12a and 12c, the regions with the most significant changes in SST were concentrated in the mid- to high-latitude North Atlantic (especially around Greenland), where significant SST warming, whether in the dry or wet season, was observed. Hence, we defined the area with the most significant change in SST as the key region $\left(50^{\circ}-67^{\circ} \mathrm{N}, 10^{\circ}-63^{\circ} \mathrm{W}\right.$ for the wet season; $60^{\circ}-75^{\circ} \mathrm{N}, 28^{\circ}-60^{\circ} \mathrm{W}$ for the dry season). The regions enclosed by red solid lines in Figs. $12 \mathrm{a}$ and $12 \mathrm{c}$ were selected to calculate the area-averaged SST. Figures $12 \mathrm{~b}$ and $12 \mathrm{~d}$ display the regression coefficients between the SST averaged over the key region and 200-hPa geopotential height in wet and dry seasons on interdecadal time scales. The featured anticyclonic and cyclonic anomalies were very similar to the difference in eddy $200-\mathrm{hPa}$ geopotential height between 1982-2000 and 2001-19 in the wet and dry seasons (Figs. 9a,b and 12b,d). These results imply that SST anomalies near Greenland may influence atmospheric circulation over CA through an extratropical large-scale anomalous wave train. Atlantic SST changes were highly related to AMO variations (Sutton and Dong 2012; Si and Ding 2016). This circulation anomaly in the dry season found in this study is consistent with the results in Sun et al. (2020) and C. Zhou et al. (2019), who mentioned that the AMO warm phase induced a series of high pressure and low pressure systems over Eurasia at $200 \mathrm{hPa}$ in summer during 1979-2019. Our analysis only indicates that the mid-to-high North Atlantic SST anomaly had a high correlation with the interdecadal 
variations in precipitation by linkage with anomalous atmospheric circulations, but the potential mechanism of the atmosphere-ocean interactions needs further research. In addition, It should be mentioned that a significant negative anomaly existed in the central-eastern equatorial Pacific for the wet season (Fig. 12a), which represents not La Niña but rather a tropical Pacific decadal variability.

On interannual time scales, ENSO has important influence on the wet and dry climate in CA (Hoell et al. 2017). Two of the most severe widespread droughts in southwestern Asia during 1999-2001 and 2007-08 were associated with La Niña conditions, with a pattern of cold SST anomalies in the central and eastern Pacific and warm SST anomalies in the western Pacific and eastern Indian Ocean (Barlow et al. 2002, 2016; Hoell et al. 2020). Enhanced tropical Indo-west Pacific Ocean convection results in latent heat release increases, which excite stationary Rossby waves. Rossby waves have a thermodynamic influence on vertical motion and moisture transport suppresses precipitation over southwestern Asia. For El Niño, it has a positive influence on the wet season precipitation in central Southwest Asia (CSWA) at a seasonal time scale. On the one hand, the abnormally high sea temperatures in the middle-east Pacific caused the Rossby wave-like pattern, which led to the anomalous upper-level trough persisting over CSWA in November and April; on the other hand, the ENSO forced the diabatic heating anomalies over the Indian Ocean, with the abnormal warming over the western Indian Ocean and the abnormal cooling over the eastern Indian Ocean, which also exhibited a Rossby wave-like pattern with an upper-level trough over CSWA and enhanced moisture flux from the Indian Ocean toward the CSWA region. When the direct and indirect effects were in the same phase, they commonly strengthened the precipitation over CSWA by intensifying the subtropical jet and making it move southward (Abid et al. 2020). The warming of the tropical Indian Ocean in summer weakened the South Asian monsoon and reduced summer precipitation over Indian regions leading to less release of latent heat, which also produces a similar effect to that in the wet season and enhanced the summer rainfall in CA (Meng et al. 2021). In addition, during El Niño, the Madden-Julian oscillation was more active than during La Niña, the different phases of which have different influences on the dynamic and thermodynamic mechanisms of the regional extreme precipitation over Karakoram and the western Himalayas (Cannon et al. 2017). On long-term time scales, the long-term drying of the region is associated with Indo-Pacific warming, which forces an anticyclone over southwestern Asia and results in reduced precipitation during winter (Hoell et al. 2015, 2017).

Our above results showed that altered SST conditions are likely to change the wet and dry climate in CA. However, due to the relatively short study period, the effect of vegetation was not considered in this study. Previous investigations have shown that severely sparse vegetation degradation was found in the Ustyurt Plateau, the Karakum and Kyzylkum Deserts, the Ustyurt Plateau, and the wetland delta of the South (Large) Aral Sea from 1984 to 2013 (Jiang et al. 2017). The growing season NDVI was also shown to have decreased by
$-0.0095 \pm 0.0065$ per decade from 1982 to 2015 (Deng et al. 2020), and 1998 was the turning point (Li et al. 2015). In addition, the regional precipitation variability of the preceding cold season also has a strong influence on vegetation growth during the warm season (Barlow and Tippett 2008). Vegetation growth is strongly constrained by precipitation in arid regions, while it can also affect the distribution of precipitation between evaporation and runoff. Therefore, an explicit estimation of the role of vegetation and land cover in the hydrological cycle can be studied. Since it is difficult to obtain observational data for multiple variables, we utilized reanalysis data for calculations. This limitation may be overcome by using site-observation data, which may also improve the reliability of risk assessment in future work.

Global warming has accelerated the global water cycle (Sun et al. 2007; IPCC 2013), and the relationships among evapotranspiration, water vapor transportation, and precipitation at different scales may vary to a certain extent (Trenberth et al. 2003). Alteration of the allocation proportion of local evaporation and externally advected moisture for local precipitation inseparably affect the production of water resources. Our findings provide a comprehensive picture of $P-E$ trends for the past 40 years, but future changes in the water cycle are still uncertain. For global land monsoon regions, future global warming would intensify the water cycle, with the wet season getting wetter and the dry season getting drier (W. Zhang et al. 2019). For arid and semiarid regions, total precipitation and extreme precipitation are projected to exhibit a robust increasing trend (Huang et al. 2014; Jiang et al. 2020b; Yao et al. 2020a), especially during the cold season over CA in the twenty-first century, which is closely related to the enhancement of local evaporation ( $\mathrm{Yu}$ et al. 2018). If contrasts between the wet and dry seasons continue, agricultural production will be significantly affected and the occurrence frequency of drought and floods will increase. From 1988 to 2007, natural hazards affecting the population in CA were dominated by droughts $(70 \%$ contribution), followed by floods (19\% contribution) (Thurman 2011). As natural disasters result in significant economic losses, we suggest that variations in hydroclimatic conditions should be a main area of research to assess possible future ecosystem impacts, which is essential for developing adaptation strategies to deal with climate change and maintain sustainable development in these sensitive areas (Huang et al. 2020). In addition, measures should be undertaken to reduce region vulnerability, such as improving accessibility of hydrological data and formulating more sustainable water resource management.

Acknowledgments. This work was jointly supported by the National Natural Science Foundation of China (41991231, 42075043), Strategic Priority Research Program of Chinese Academy of Sciences (XDA2006010301) and the Youth Innovation Promotion Association CAS. This work was also supported by the Supercomputing Center of Lanzhou University.

Data availability statement. JRA-55 reanalysis products can be downloaded at https://rda.ucar.edu/datasets/ds628.0/. 
ERA5 reanalysis products are archived at https://cds.climate. copernicus.eu/cdsapp\#!/dataset/reanalysis-era5-single-levelsmonthly-means?tab=form. MERRA-2 reanalysis products are accessed at https:/gmao.gsfc.nasa.gov/reanalysis/MERRA2/data_access/. CRU precipitation data are available at https:// catalogue.ceda.ac.uk/uuid/10d3e3640f004c578403419aac167d82. GPCC data can be obtained from https://psl.noaa.gov/data/ gridded/data.gpcc.html. PREC/L precipitation data can be obtained from the Physical Science Division of the Earth Systems Research Laboratory of NOAA (NOAA/ESRL/PSD; http://www.esrl.noaa.gov/psd/data/gridded/data.precl.html). The PML_V2 and EB-ET evapotranspiration dataset are provided by the National Tibetan Plateau Data Center (http://data.tpdc. ac.cn). GLEAM v3 evapotranspiration data are available from the GLEAM homepage: https://www.gleam.eu/. GLDAS data are available at https://disc.gsfc.nasa.gov/datasets?keywords= GLDAS. NDVI data can be obtained from https:// climatedataguide.ucar.edu/climate-data/ndvi-normalizeddifference-vegetation-index-3rd-generation-nasagfsc-gimms. ERSST data can be downloaded from https://www.ncdc. noaa.gov/data-access/marineocean-data/extended-reconstructedsea-surface-temperature-ersst-v5.

\section{REFERENCES}

Abid, M. A., M. Ashfaq, F. Kucharski, K. J. Evans, and M. Almazroui, 2020: Tropical Indian Ocean mediates ENSO influence over central southwest Asia during the wet season. Geophys. Res. Lett., 47, e2020GL08930, https://doi.org/10. 1029/2020GL089308.

Allen, R. G., L. S. Pereira, D. Raes, and M. Smith, 1998: Crop evapotranspiration: Guidelines for computing crop water requirements. FAO Irrigation and Drainage Paper 56, 174 pp.

Aralova, D., J. Kariyeva, T. Khujanazarov, and K. Toderich, 2018: Drought variability and land degradation in central Asia: Assessment using remote sensing data and drought indices. Vegetation of Central Asia and Environs, D. Egamberdieva and M. Öztürk, Eds., Springer, 15-47, https://doi.org/10.1007/ 978-3-319-99728-5_2.

Barlow, M., and M. K. Tippett, 2008: Variability and predictability of central Asia river flows: Antecedent winter precipitation and large-scale teleconnections. J. Hydrometeor., 9, 1334 1349, https://doi.org/10.1175/2008JHM976.1.

- H. Cullen, and B. Lyon, 2002: Drought in central and southwest Asia: La Niña, the warm pool, and Indian Ocean precipitation. J. Climate, 15, 697-700, https://doi.org/10.1175/15200442(2002)015<0697:DICASA > 2.0.CO;2.

— B. Zaitchik, S. Paz, E. Black, J. Evans, and A. Hoell, 2016: A review of drought in the Middle East and Southwest Asia. J. Climate, 29, 8547-8574, https://doi.org/10.1175/JCLI-D-1300692.1.

Becker, A., P. Finger, A. Meyer-Christoffer, B. Rudolf, K. Schamm, U. Schneider, and M. Ziese, 2013: A description of the global land-surface precipitation data products of the Global Precipitation Climatology Centre with sample applications including centennial (trend) analysis from 1901-present. Earth Syst. Sci. Data, 5, 71-99, https://doi.org/10.5194/essd-571-2013.
Bisselink, B., and A. J. Dolman, 2008: Precipitation recycling: Moisture sources over Europe using ERA-40 data. J. Hydrometeor., 9, 1073-1083, https://doi.org/10.1175/2008JHM962.1.

Budyko, M. I., 1974: Climate and Life. D. H. Miller, Ed., International Geophysics Series, Vol. 18, Academic Press, 508 pp.

Cannon, F., L. M. V. Carvalho, C. Jones, A. Hoell, J. Norris, G. N. Kiladis, and A. A. Tahir, 2017: The influence of tropical forcing on extreme winter precipitation in the western Himalaya. Climate Dyn., 48, 1213-1232, https://doi.org/10. 1007/s00382-016-3137-0.

Chen, F., J. Wang, and L. Jin, 2009: Rapid warming in mid-latitude central Asia for the past 100 years. Front. Earth Sci. China, 3, 42-50, https://doi.org/10.1007/s11707-009-0013-9.

— W. Wuang, L. Jin, J. Chen, and J. Wang, 2011: Spatiotemporal precipitation variations in the arid central Asia in the context of global warming. Sci. China Earth Sci., 54, 1812-1821, https://doi.org/10.1007/s11430-011-4333-8.

Chen, X. L., Z. Su, Y. Ma, K. Yang, J. Wen, and Y. Zhang, 2013: An improvement of roughness height parameterization of the Surface Energy Balance System (SEBS) over the Tibetan Plateau. J. Appl. Meteor. Climatol., 52, 607-622, https://doi. org/10.1175/JAMC-D-12-056.1.

_ W. W. Massman, and Z. Su, 2019: A column canopy-air turbulent diffusion method for different canopy structures. $J$. Geophys. Res. Atmos., 124, 488-506, https://doi.org/10.1029/ 2018JD028883.

Chen, Y., Z. Li, Y. Fan, H. Wang, and H. Deng, 2015: Progress and prospects of climate change impacts on hydrology in the arid region of northwest China. Environ. Res., 139, 11-19, https://doi.org/10.1016/j.envres.2014.12.029.

,,-- W. Li, H. Deng, and Y. Shen, 2016: Water and ecological security: Dealing with hydroclimatic challenges at the heart of China's Silk Road. Environ. Earth Sci., 75, 881, https://doi.org/10.1007/s12665-016-5385-z.

Chou, C., J. C. H. Chiang, C. W. Lan, C. H. Chung, Y. C. Liao, and C. J. Lee, 2013: Increase in the range between wet and dry season precipitation. Nat. Geosci., 6, 263-267, https://doi. org/10.1038/ngeo1744.

Choudhury, B. J., 1999: Evaluation of an empirical equation for annual evaporation using field observations and results from a biophysical model. J. Hydrol., 216, 99-110, https://doi.org/ 10.1016/S0022-1694(98)00293-5.

Deng, H., and Y. Chen, 2017: Influences of recent climate change and human activities on water storage variations in central Asia. J. Hydrol., 544, 46-57, https://doi.org/10.1016/j.jhydrol. 2016.11.006.

-, Y. Yin, and X. Han, 2020: Vulnerability of vegetation activities to drought in central Asia. Environ. Res. Lett., 15, 084005, https://doi.org/10.1088/1748-9326/ab93fa.

Dominguez, F., P. Kumar, X.-Z. Liang, and M. Ting, 2006: Impact of atmospheric moisture storage on precipitation recycling. $J$. Climate, 19, 1513-1530, https://doi.org/10.1175/JCLI3691.1.

Feng, T., T. Su, F. Ji, R. Zhi, and Z. Han, 2018: Temporal characteristics of actual evapotranspiration over China under global warming. J. Geophys. Res. Atmos., 123, 5845-5858, https:// doi.org/10.1029/2017JD028227.

Fu, B. P., 1981: On the calculation of the evaporation from land surface. Chin. J. Atmos. Sci., 5, 23-31, https://doi.org/10.3878/ j.issn.1006-9895.1981.01.03.

Gao, X., M. Sun, Q. Luan, X. Zhao, J. Wang, G. He, and Y. Zhao, 2020: The spatial and temporal evolution of the actual evapotranspiration based on the remote sensing method in 
the Loess Plateau. Sci. Total Environ., 708, 135111, https:// doi.org/10.1016/j.scitotenv.2019.135111.

Gelaro, R., and Coauthors, 2017: The Modern-Era Retrospective Analysis for Research and Applications, version 2 (MERRA2). J. Climate, 30, 5419-5454, https://doi.org/10.1175/JCLI-D16-0758.1.

Gerlitz, L., E. Steirou, C. Schneider, V. Moron, S. Vorogushyn, and B. Merz, 2018: Variability of the cold season climate in central Asia. Part I: Weather types and their tropical and extratropical drivers. J. Climate, 31, 7185-7207, https://doi. org/10.1175/JCLI-D-17-0715.1.

Greve, P., B. Orlowsky, B. Mueller, J. Sheffield, M. Reichstein, and S. I. Seneviratne, 2014: Global assessment of trends in wetting and drying over land. Nat. Geosci., 7, 716-721, https://doi.org/10.1038/ngeo2247.

He, Y., T. Yang, and Q. Ji, 2015: Glacier variation in response to climate change in Chinese Tianshan Mountains from 1989 to 2012. J. Mt. Sci., 12, 1189-1202, https://doi.org/10.1007/s11629015-3445-6.

Held, I. M., and B. J. Soden, 2006: Robust responses of the hydrological cycle to global warming. J. Climate, 19, 5686-5699, https://doi.org/10.1175/JCLI3990.1.

Hoell, A., C. Funk, and M. Barlow, 2015: The forcing of southwestern Asia teleconnections by low-frequency sea surface temperature variability during boreal winter. J. Climate, 28, 1511-1526, https://doi.org/10.1175/JCLI-D-14-00344.1.

- M. Barlow, F. Cannon, and T. Xu, 2017: Oceanic origins of historical southwest Asia precipitation during the boreal cold season. J. Climate, 30, 2885-2903, https://doi.org/10.1175/ JCLI-D-16-0519.1.

—, J. Eischeid, M. Barlow, and A. McNally, 2020: Characteristics, precursors, and potential predictability of Amu Darya Drought in an Earth system model large ensemble. Climate Dyn., 55, 2185-2206, https://doi.org/10.1007/s00382-020-05381-5.

$\mathrm{Hu}$, Z., C. Zhang, Q. Hu, and H. Tian, 2014: Temperature changes in central Asia from 1979-2011 based on multiple datasets. J. Climate, 27, 1143-1167, https://doi.org/10.1175/ JCLI-D-13-00064.1.

—, X. Chen, D. Chen, J. Li, S. Wang, Q. Zhou, G. Yin, and M. Guo, 2018: "Dry gets drier, wet gets wetter": A case study over the arid regions of central Asia. Int. J. Climatol., 39, 1072-1091, https://doi.org/10.1002/joc.5863.

Hua, L., L. Zhong, and Z. Ke, 2016: Precipitation recycling and soil-precipitation interaction across the arid and semi-arid regions of China. Int. J. Climatol., 36, 3708-3722, https://doi. org/10.1002/joc. 4586 .

- - -, and Z. Ma, 2017: Decadal transition of moisture sources and transport in northwestern China during summer from 1982 to 2010. J. Geophys. Res. Atmos., 122, 12522-12540, https://doi.org/10.1002/2017JD027728.

Huang, D., Y. Zhang, Y. Zhou, A. Huang, Y. Zhao, and H. Wu, 2014: Changes of the annual precipitation over central Asia in the twenty-first century projected by multimodels of CMIP5. J. Climate, 27, 6627-6646, https://doi.org/10.1175/ JCLI-D-14-00070.1.

Huang, J., H. Yu, X. Guan, G. Wang, and R. Guo, 2016: Accelerated dryland expansion under climate change. Nat. Climate Change, 6, 166-171, https://doi.org/10.1038/nclimate2837.

— , and Coauthors, 2020: Declines in global ecological security under climate change. Ecol. Indic., 117, 106651, https://oi. org/10.1016/j.ecolind.2020.106651.

Huang, W., S. Feng, J. Chen, and F. Chen, 2015: Physical mechanisms of summer precipitation variations in the Tarim Basin in northwestern China. J. Climate, 28, 3579-3591, https://doi. org/10.1175/JCLI-D-14-00395.1.

IPCC, 2013: Climate Change 2013: The Physical Science Basis. Cambridge University Press, 1535 pp., https://doi.org/10.1017/ CBO9781107415324.

Jiang, J., T. Zhou, H. Wang, Y. Qian, D. Noone, and W. Man, 2020a: Tracking moisture sources of precipitation over central Asia: A study based on the water-source-tagging method. $J$. Climate, 33, 10339-10355, https://doi.org/10.1175/JCLI-D-200169.1.

,,-- X. Chen, and L. Zhang, 2020b: Future changes in precipitation over central Asia based on CMIP6 projections. Environ. Res. Lett., 15, 054009, https://doi.org/10.1088/17489326/ab7d03.

Jiang, L., J. Guli, A. Bao, H. Guo, and F. Ndayisaba, 2017: Vegetation dynamics and responses to climate change and human activities in central Asia. Sci. Total Environ., 599-600, 967980, https://doi.org/10.1016/j.scitotenv.2017.05.012.

Kobayashi, S., and Coauthors, 2015: The JRA-55 reanalysis: General specifications and basic characteristics. J. Meteor. Soc. Japan, 93, 5-48, https://doi.org/10.2151/jmsj.2015-001.

Li, B., Y. Chen, Z. Chen, H. Xiong, and L. Lian, 2016: Why does precipitation in northwest China show a significant increasing trend from 1960 to 2010? Atmos. Res., 167, 275-284, https:// doi.org/10.1016/j.atmosres.2015.08.017.

Li, D., M. Pan, Z. Cong, L. Zhang, and E. Wood, 2013: Vegetation control on water and energy balance within the Budyko framework. Water Resour. Res., 49, 969-976, https://doi.org/ 10.1002/wrcr.20107.

Li, S., J. Perlwitz, X. Quan, and M. P. Hoerling, 2008: Modelling the influence of North Atlantic multidecadal warmth on the Indian summer rainfall. Geophys. Res. Lett., 35, L05804, https://doi.org/10.1029/2007GL032901.

Li, T., J. Xia, D. She, L. Cheng, L. Zou, and B. Liu, 2020: Quantifying the impacts of climate change and vegetation variation on actual evapotranspiration based on the Budyko hypothesis in North and South Panjiang Basin, China. Water, 12, 508, https://doi.org/10.3390/w12020508.

Li, Z., Y. Chen, W. Li, H. Deng, and G. Fang, 2015: Potential impacts of climate change on vegetation dynamics in central Asia. J. Geophys. Res. Atmos., 120, 12345-12 356, https://doi. org/10.1002/2015JD023618.

,$--1-$ G. Fang, and Y. Li, 2017: Multivariate assessment and attribution of droughts in central Asia. Sci. Rep., 7, 1316, https://doi.org/10.1038/s41598-017-01473-1.

Ma, Q., J. Zhang, A. T. Game, Y. Chang, and S. Li, 2020: Spatiotemporal variability of summer precipitation and precipitation extremes and associated large-scale mechanisms in central Asia during 1979-2018. J. Hydrol. X, 8, 100061, https:// doi.org/10.1016/j.hydroa.2020.100061.

Martens, B., and Coauthors, 2017: GLEAM v3: Satellite-based land evaporation and root-zone soil moisture. Geosci. Model Dev., 10, 1903-1925, https://doi.org/10.5194/gmd-10-1903-2017.

- W. Waegeman, W. A. Dorigo, N. E. C. Verhoest, and D. G. Miralles, 2018: Terrestrial evaporation response to modes of climate variability. Climate Atmos. Sci., 1, 43, https://doi.org/ 10.1038/s41612-018-0053-5.

Martinez, T. A., and F. Dominguez, 2014: Sources of atmospheric moisture for the La Plata River basin. J. Climate, 27, 67376753, https://doi.org/10.1175/JCLI-D-14-00022.1.

Martius, O., and Coauthors, 2013: The role of upper-level dynamics and surface processes for Pakistan flood of July 2010. 
Quart. J. Roy. Meteor. Soc., 139, 1780-1797, https://doi.org/10. 1002/qj.2082.

Meng, L., Y. Zhao, and M. Li, 2021: Effects of whole SST anomaly in the tropical Indian Ocean on summer rainfall over central Asia. Front. Earth Sci., 9, 738066, https://doi.org/10.3389/ feart.2021.738066.

Miralles, D. G., and Coauthors, 2013: El Niño-La Niña cycle and recent trends in continental evaporation. Nat. Climate Change, 4, 122-126, https://doi.org/10.1038/nclimate2068.

Peng, D., and T. Zhou, 2017: Why was the arid and semiarid northwest China getting wetter in the recent decades? J. Geophys. Res. Atmos., 122, 9060-9075, https://doi.org/10.1002/ 2016JD026424.

,-- , L. Zhang, and B. Wu, 2018: Human contribution to the increasing summer precipitation in central Asia from 1961 to 2013. J. Climate, 31, 8005-8021, https://doi.org/10. 1175/JCLI-D-17-0843.1.

,,,--- , and L. Zou, 2019: Detecting human influence on the temperature changes in central Asia. Climate Dyn., 53, 4553-4568, https://doi.org/10.1007/s00382-019-04804-2.

,-- , and,- 2020 : Moisture sources associated with precipitation during dry and wet seasons over central Asia. $J$. Climate, 33, 10 755-10771, https://doi.org/10.1175/JCLI-D-200029.1.

Roderick, M. L., and G. D. Farquhar, 2011: A simple framework for relating variations in runoff to variations in climatic conditions and catchment properties. Water Resour. Res., 47, W00G07, https://doi.org/10.1029/2010WR009826.

— , F. Sun, W. H. Lim, and G. D. Farquhar, 2014: A general framework for understanding the response of the water cycle to global warming over land and ocean. Hydrol. Earth Syst. Sci., 18, 1575-1589, https://doi.org/10.5194/hess-18-1575-2014.

Schiemann, R., D. Lüthi, P. Vidale and C. Schar, 2008: The precipitation climate of Central Asia-Intercomparison of observational and numerical data sources in a remote semiarid region. Int. J. Climatol., 28, 295-314, https://doi.org/10. 1002/joc.1532.

Shi, Y., Y. Shen, E. Kang, D. Li, Y. Ding, G. Zhang, and R. Hu, 2007: Recent and future climate change in northwest China. Climatic Change, 80, 379-393, https://doi.org/10.1007/s10584006-9121-7.

Si, D., and Y. H. Ding, 2016: Oceanic forcings of the interdecadal variability in East Asian summer rainfall. J. Climate, 29, 7633-7649, https://doi.org/10.1175/JCLI-D-15-0792.1.

Sodemann, H., C. Schwierz, and H. Wernli, 2008: Interannual variability of Greenland winter precipitation sources: Lagrangian moisture diagnostic and North Atlantic Oscillation influence. J. Geophys. Res., 113, D03107, https://doi.org/10.1029/ 2007JD008503.

Su, T., T. Feng, and G. Feng, 2015: Evaporation variability under climate warming in five reanalyses and its association with pan evaporation over China. J. Geophys. Res. Atmos., 120, 8080-8098, https://doi.org/10.1002/2014JD023040.

Sui, C., X. Li, M. Yang, and H. Huang, 2005: Estimation of oceanic precipitation efficiency in cloud models. J. Atmos. Sci., 62, 4358-4370, https://doi.org/10.1175/JAS3587.1.

,-- , and,- 2007 : On the definition of precipitation efficiency. J. Atmos. Sci., 64, 4506-4513, https://doi.org/10.1175/ 2007JAS2332.1.

Sun, B., and H. Wang, 2014: Moisture sources of semiarid grassland in China using the Lagrangian particle model FLEXPART. J. Climate, 27, 2457-2474, https://doi.org/10.1175/ JCLI-D-13-00517.1.
Sun, J., K. Yang, W. Guo, Y. Wang, J. He, and H. Lu, 2020: Why has the inner Tibetan Plateau become wetter since the mid1990s? J. Climate, 33, 8507-8522, https://doi.org/10.1175/JCLID-19-0471.1.

Sun, Y., S. Solomon, A. Dai, and R. Portmann, 2007: How often will it rain? J. Climate, 20, 4801-4818, https://doi.org/10.1175/ JCLI4263.1.

Sutton, R. T., and B. Dong, 2012: Atlantic Ocean influence on a shift in European climate in the 1990s. Nat. Geosci., 5, 788792, https://doi.org/10.1038/ngeo1595.

Syed, F. S., F. Giorgi, J. S. Pal, and K. Keay, 2010: Regional climate model simulation of winter climate over centralsouthwest Asia, with emphasis on NAO and ENSO effects. Int. J. Climatol., 30, 220-235, https://doi.org/10.1002/joc.1887.

Ta, Z., R. Liu, X. Chen, G. Mu, and Y. Guo, 2018: Analysis of the spatio-temporal patterns of dry and wet conditions in central Asia. Atmosphere, 9, 7, https://doi.org/10.3390/ atmos 9010007.

Thurman, M., 2011: Natural disaster risks in central Asia: A synthesis. United Nations Development Programme, $40 \mathrm{pp}$.

Tian, L., J. Jin, P. Wu, and G. Y. Niu, 2018: Quantifying the impact of climate change and human activities on streamflow in a semi-arid watershed with the Budyko equation incorporating dynamic vegetation information. Water, 10, 1781, https://doi.org/10.3390/w10121781.

Trenberth, K. E., A. Dai, R. M. Rasmussen, and D. B. Parsons, 2003: The changing character of precipitation. Bull. Amer. Meteor. Soc., 84, 1205-1218, https://doi.org/10.1175/BAMS84-9-1205.

Van der Ent, R. J., and H. H. G. Savenije, 2013: Oceanic sources of continental precipitation and the correlation with sea surface temperature. Water Resour. Res., 49, 3993-4004, https:// doi.org/10.1002/wrcr.20296.

Wang, D., and M. Hejazi, 2011: Quantifying the relative contribution of the climate and direct human impacts on mean annual streamflow in the contiguous United States. Water Resour. Res., 47, W00J12, https://doi.org/10.1029/2010WR010283.

Wang, Q., P.-M. Zhai, and D.-H. Qin, 2020: New perspectives on 'warming-wetting' trend in Xinjiang, China. Adv. Climate Change Res., 11, 252-260, https://doi.org/10.1016/j.accre.2020. 09.004 .

Wang, S., M. Zhang, Y. Che, F. Chen, and F. Qiang, 2016: Contribution of recycled moisture to precipitation in oases of arid central Asia: A stable isotope approach. Water Resour. Res., 52, 3246-3257, https://doi.org/10.1002/2015WR018135.

Wang, W., and Coauthors, 2016: The analytical derivation of multiple elasticities of runoff to climate change and catchment characteristics alteration. J. Hydrol., 541, 1042-1056, https:// doi.org/10.1016/j.jhydrol.2016.08.014.

Weier, J., and D. Herring, 2000: Measuring vegetation (NDVI \& EVI). NASA Earth Observatory, accessed 12 August 2021, https://earthobservatory.nasa.gov/features/MeasuringVegetation/ measuring_vegetation_2.php.

Wu, J., C. Miao, Y. Wang, Q. Duan, and X. Zhang, 2017: Contribution analysis of the long-term changes in seasonal runoff on the Loess Plateau, China, using eight Budyko-based methods. J. Hydrol., 545, 263-275, https://doi.org/10.1016/j.jhydrol. 2016.12.050.

Wu, P., Y. Ding, Y. Liu, and X. Li, 2019: The characteristics of moisture recycling and its impact on regional precipitation against the background of climate warming over Northwest China. Int. J. Climatol., 39, 5241-5255, https://doi.org/10.1002/ joc.6136. 
Xu, X., D. Yang, H. Yang, and H. Lei, 2014: Attribution analysis based on the Budyko hypothesis for detecting the dominant cause of runoff decline in Haihe basin. J. Hydrol., 510, 530540, https://doi.org/10.1016/j.jhydrol.2013.12.052.

Yang, H., D. Yang, Z. Lei, and F. Sun, 2008: New analytical derivation of the mean annual water-energy balance equation. Water Resour. Res., 44, W03410, https://doi.org/10.1029/ 2007WR006135.

—, G. Xu, H. Mao, and Y. Wang, 2020: Spatiotemporal variation in precipitation and water vapor transport over central Asia in winter and summer under global warming. Front. Earth Sci., 8, 297, https://doi.org/10.3389/feart.2020.00297.

Yang, P., and Y. Chen, 2015: An analysis of terrestrial water storage variations from GRACE and GLDAS: The Tianshan Mountains and its adjacent areas, central Asia. Quat. Int., 358, 106-112, https://doi.org/10.1016/j.quaint.2014.09.077.

Yao, J., C. Yaning, J. Chen, Y. Zhao, D. Tuoliewubieke, J. Li, L. Yang, and W. Mao, 2020a: Intensification of extreme precipitation in arid central Asia. J. Hydrol., 598, 125760, https://doi. org/10.1016/j.jhydrol.2020.125760.

—, Y. Chen, Y. Zhao, X. Guan, W. Mao, and L. Yang, 2020b: Climatic and associated atmospheric water cycle changes over the Xinjiang, China. J. Hydrol., 585, 124823, https://doi. org/10.1016/j.jhydrol.2020.124823.

Yapiyev, V., and Coauthors, 2017: The changing water cycle: Burabay National Nature Park, northern Kazakhstan. Wiley Interdiscip. Rev.: Water, 4, e1227, https://doi.org/10.1002/wat2. 1227.

— , and Coauthors, 2019: Estimation of water storage changes in small endorheic lakes in northern Kazakhstan. J. Arid Environ., 160, 42-55, https://doi.org/10.1016/j.jaridenv.2018.09. 008.

Yin, G., Z. Hu, X. Chen, and T. Tiyip, 2016: Vegetation dynamics and its response to climate change in central Asia. J. Arid Land, 8, 375-388, https://doi.org/10.1007/s40333-016-0043-6.
Yin, Z.-Y., H. Wang, and X. Liu, 2014: A comparative study on precipitation climatology and interannual variability in the lower midlatitude east Asia and central Asia. J. Climate, 27, 7830-7848, https://doi.org/10.1175/JCLI-D-14-00052.1.

$\mathrm{Yu}, \mathrm{Y}$., and Coauthors, 2018: Climate change, water resources and sustainable development in the arid and semi-arid lands of central Asia in the past 30 years. J. Arid Land, 11, 1-14, https://doi.org/10.1007/s40333-018-0073-3.

Zhang, J., Q. Ma, H. Chen, S. Zhao, and Z. Chen, 2021: Increasing warm-season precipitation in Asian drylands and response to reducing spring snow cover over the Tibetan Plateau. J. Climate, 34, 3129-3144, https://doi.org/10.1175/JCLID-20-0479.1.

Zhang, W., T. Zhou, L. Zhang, and L. Zou, 2019: Future intensification of the water cycle with an enhanced annual cycle over global land monsoon regions. J. Climate, 32, 5437-5451, https://doi.org/10.1175/JCLI-D-18-0628.1.

Zhang, Y., and J. Sun, 2012: Model projections of precipitation minus evaporation in China. Acta Meteor. Sin., 26, 376-388, https://doi.org/10.1007/s13351-012-0309-7.

— , D. Kong, R. Gan, F. H. S. Chiew, T. R. McVicar, Q. Zhang, and Y. Yang, 2019: Coupled estimation of $500 \mathrm{~m}$ and 8-day resolution global evapotranspiration and gross primary production in 2002-2017. Remote Sens. Environ., 222, 165-182, https://doi.org/10.1016/j.rse.2018.12.031.

Zhou, C., P. Zhao, and J. Chen, 2019: The interdecadal change of summer water vapor over the Tibetan Plateau and associated mechanisms. J. Climate, 32, 4103-4119, https://doi.org/10. 1175/JCLI-D-18-0364.1.

Zhou, Y.-S., Z. Xie, and X. Liu, 2019: An analysis of moisture sources of torrential rainfall events over Xinjiang, China. $J$. Hydrometeor., 20, 2109-2122, https://doi.org/10.1175/JHM-D19-0010.1. 